\title{
LA CONFIGURACIÓN JURISPRUDENCIAL DE LOS DERECHOS FUNDAMENTALES. EL CASO DEL DERECHO CONSTITUCIONAL A UNA DEFENSA ADECUADA
}

\begin{abstract}
RESUMEN: El artículo cuestiona el quehacer de la Suprema Corte y los tribunales colegiados de circuito para modificar las prácticas autoritarias que han caracterizado la labor de ministerios públicos y jueces penales por muchos años. Se analiza la construcción jurisprudencial del derecho constitucional del inculpado a contar con una "adecuada defensa". En primer término, se revisa el nivel de eficacia del derecho a la defensa en las agencias del Ministerio Público y los juzgados penales. En la segunda parte, se realiza un estudio cuantitativo y cualitativo de las tesis aisladas y jurisprudenciales de la Novena Época en esta materia. Dicho estudio nos permite concluir que las nuevas coordenadas democráticas del país no han impactado de forma cabal la manera como estos jueces conciben su papel y su función. Este es el mayor desafío que tiene enfrente el Poder Judicial federal. No hay nada más difícil de lograr, en términos de una reforma judicial, que modificar la mentalidad de los jueces y el método para argumentar sus decisiones.
\end{abstract}

Palabras clave: Suprema Corte, tribunales colegiados de circuito, garantías individuales, derechos humanos, Ministerio Público, jueces.

\section{Ana Laura MAGALONI KERPEL* Ana María IBARRA OLGUÍN**}

ABSTRACT: This article questions the task of the Supreme Court and the federal circuit courts to modify the authoritarian practices that have characterized the labors of the public prosecutor and criminal judges for several years. It is analyzed the constitutional precedents of the constitutional right to a "due defense". In fist term, it is analyzed, with the available statistics data, the level of efficiency of the right to a defense in the agency of the Public Prosecutor and in the criminal courts. In the second part, it is carried out a quantitative and qualitative study of precedents and jurisprudence. These study allows us to conclude that the new democratic coordinates in the country have not impact the way these judges conceive their paper and function. This is the greatest challenge of the Federal Judicial Power. There is nothing more difficult to obtain, in terms of a judicial reform, than to modify the mentality of the judges and the method to argue their decisions.

Descriptors: Supreme Court, federal circuit courts, constitutional rights, human rights, Public Prosecutor, judges.

* Profesora-investigadora en la División de Estudios Jurídicos del Centro de Investigación y Docencia Económicas.

** Licenciada en derecho por el Centro de Investigación y Docencia Económicas.

Fecha de recepción: 14 de febrero de 2008.

Fecha de dictamen: 10 de junio de 2008 . 


\section{INTRODUCCIÓN}

Este artículo pretende relacionar dos mundos que en el debate público y académico generalmente se analizan en forma separada. Por un lado, las prácticas autoritarias que prevalecen en la procuración e impartición de justicia penal en México y, por el otro, la función de la Suprema Corte de Justicia y los tribunales colegiados de circuito como intérpretes últimos de la Constitución. Resulta llamativo, por decir lo menos, que en el debate público se discuta la sistemática ineficacia de los derechos constitucionales del acusado y de la víctima en los procesos penales del país y que, al mismo tiempo, pase completamente desapercibido que una de las funciones principales de la Suprema Corte y los tribunales colegiados es interpretar y garantizar la eficacia de tales derechos. Nuestro argumento central es que los niveles de arbitrariedad que prevalecen en la justicia penal del país se explican, en parte, por la inadecuada configuración jurisprudencial de los derechos constitucionales del acusado por parte de la Corte y los tribunales colegiados. Dicho de otra manera, la jurisprudencia constitucional en relación con el debido proceso no ha dotado de contenido sustantivo a los derechos del acusado, tampoco ha colocado los incentivos adecuados para que los jueces y ministerios públicos modifiquen sus conductas autoritarias.

Para demostrar lo anterior, vamos a analizar la manera como la Suprema Corte y los tribunales colegiados de circuitio han interpretado el derecho constitucional a la defensa, establecido en el artículo 20, fracciones IX y X de la Constitución. Para ello analizaremos, en primer término, algunas de las características que definen a la jurisprudencia constitucional en Europa y Estados Unidos y cómo esas características están ausentes en el caso de la jurisprudencia mexicana. En segundo término, vamos a estudiar, a partir de los datos disponibles, cuál es el nivel de eficacia del derecho a la defensa en la práctica cotidiana de los ministerios públicos y juzgados penales. Como se verá, la evidencia empírica demuestra que el derecho a la defensa es altamente ineficaz. En la tercera parte, analizaremos y sistematizaremos todas las tesis aisladas y jurisprudenciales de la Novena Época que han buscado dotar de contenido al derecho a la defensa. Lo que intentaremos demostrar es que dichas tesis y criterios tienen tres problemas centrales: 1) la ausencia de razonamientos sustantivos que se hagan cargo de los valores constitucionales que subyacen en el dere- 
cho a la defensa, 2) la inexistencia de un razonamiento concatenado entre las distintas jurisprudencias y 3) la ausencia de costos o consecuencias legales en el proceso producto de la mala calidad de la defensa. Todo ello explica por qué en México, a pesar del cambio político, los ministerios públicos y los jueces penales no han modificado sus prácticas autoritarias en esta materia.

Estamos concientes de los límites de nuestro análisis. Es imposible establecer conclusiones generales sobre la calidad de la jurisprudencia constitucional a partir del estudio de un solo derecho. Sin embargo, creemos que nuestro estudio tiene al menos tres aportaciones relevantes: 1) establece un marco teórico para comenzar a analizar las características de la jurisprudencia constitucional y la manera como ésta debería operar en la práctica judicial, 2) define y aplica un método para sistematizar y estudiar el contenido y el impacto de la jurisprudencia constitucional en México y, 3) propone una serie de argumentos para que futuros trabajos de investigación continúen explorando y buscando respuestas a la pregunta de por qué la configuración jurisprudencial de los derechos fundamentales en México no ha sido lo suficientemente robusta como para asegurar su plena eficacia.

\section{EL VALOR NORMATIVO DE LA JURISPRUDENCIA CONSTITUCIONAL}

En todos los países en donde existe un sistema de jurisdicción constitucional, determinados órganos jurisdiccionales tienen la facultad de establecer los criterios de interpretación constitucional que vinculan al resto de los tribunales. En el modelo de control constitucional concentrado es un único órgano, el Tribunal Constitucional, mientras que en el modelo de control difuso son los tribunales con jurisdicción de apelación (Tribunal Supremo y tribunales intermedios). Este último es el caso de México.

En efecto, como todos sabemos, en México la Suprema Corte de Justicia (en pleno y en salas) y los tribunales colegiados de circuito están facultados para establecer jurisprudencia vinculante para el resto de los tribunales, federales y estatales, tanto en materia constitucional como legal. ${ }^{1}$ La Corte es el órgano vértice del Poder Judicial federal y, por ello,

1 El Tribunal Electoral del Poder Judicial de la Federación también puede establecer jurisprudencia. Sin embargo, no es objeto de nuestro estudio analizar las funciones de este tribunal federal, cuya jurisprudencia se circunscribe al ámbito electoral. 
puede unificar los criterios de interpretación constitucional. Todos los tribunales del país están vinculados a su jurisprudencia. Los tribunales colegiados, en cambio, sólo generan jurisprudencia obligatoria hacia los tribunales, federales y estatales, que se encuentran dentro de su jurisdicción territorial.

En cuanto a las formas de creación de la jurisprudencia constitucional, las leyes en la materia distinguen tres tipos en función del tipo de asuntos que les dan origen. En primer término, la jurisprudencia que genera el pleno de la Corte a partir de la resolución de acciones de inconstitucionalidad y controversias constitucionales. En estos casos, las razones contenidas en los considerandos que funden los resolutivos de las sentencias serán jurisprudencia obligatoria para todos los tribunales del país, siempre que hayan estado de acuerdo con ellas ocho de los once ministros. ${ }^{2}$

En segundo término, la jurisprudencia que se genera a través de los juicios de amparo. En este caso, el carácter vinculante de los criterios de interpretación constitucional se genera por el denominado "sistema de reiteración", es decir, a través de cinco sentencias ininterrumpidas por otra en contrario. Además, se necesita un número específico de votos a favor en dichas resoluciones: en el caso del pleno, se necesitan ocho de los once ministros, en el caso de las salas, cuatro de los cinco ministros y, finalmente, tratándose de los tribunales colegiados se necesita que exista unanimidad entre los tres magistrados que integran el tribunal.

En tercer término, la jurisprudencia constitucional también se puede generar a través de las resoluciones de contradicción de tesis. En estos casos, no se requiere reiteración ni número específico de votos. El pleno resuelve las contradicciones de tesis de las salas y éstas resuelven las de los tribunales colegiados. Basta con la decisión para que se establezca un criterio de interpretación constitucional vinculante para todos los tribunales inferiores, federales y estatales. ${ }^{3}$

2 Esta forma de establecer jurisprudencia es similar a la que existe en los tribunales constitucionales europeos. Sin embargo, en el caso de México, las prácticas judiciales han inhibido la operatividad de este sistema. La jurisprudencia del pleno, producto de controversias y acciones, funciona, en la práctica, como el resto de la jurisprudencia en México.

3 Es importante destacar que la legislación en la materia no atiende el problema de las denominadas decisiones plurales, es decir, las decisiones en donde la mayoría de los ministros está de acuerdo con el fallo, pero no así con los razonamientos de la sentencia. Tal es el caso, por ejemplo, de una decisión del Pleno en donde tres ministros estén de 
Ahora bien, más allá de estas distintas formas en que se genera la jurisprudencia constitucional en México, lo más relevante, en términos de su capacidad para dotar de contenido y garantizar la eficacia de la Constitución, está en la forma en que opera en la práctica judicial el carácter vinculante de la misma. ¿Qué significa que una decisión judicial que resuelve una controversia de carácter constitucional sirva de parámetro normativo en la resolución de otros litigios?

La respuesta a esta interrogante es distinta en Estados Unidos, en Europa y en México. En este trabajo sólo destacaremos, grosso modo, cuáles son algunas de las diferencias más importantes entre México y el equivalente a la jurisprudencia constitucional en Estados Unidos y Europa. ${ }^{4}$

Una de las características centrales de la jurisprudencia constitucional en Europa y en Estados Unidos, que contrasta con el caso de México, es que, en esos países, ninguna sentencia permanece aislada. Toda decisión constitucional con valor de precedente forma parte de un cuerpo concatenado de reglas de creación judicial. Ello es particularmente cierto en materia de derechos fundamentales. Los jueces constitucionales, caso por caso, van urdiendo gradualmente la trama del sentido y alcance de cada uno de los derechos establecidos en la Constitución. Así, por ejemplo, la jurisprudencia constitucional del derecho de libre expresión se ha ido configurando, tanto en Estados Unidos como en Europa, a partir de un conjunto de asuntos que plantean distintas aristas o problemas constitucionales en torno a ese derecho: la protección constitucional al discurso político, a la propaganda comercial, a la pornografía, al discurso subversivo, etcétera. El éxito de este proceso radica en la consistencia del Tri-

acuerdo con el proyecto original, otros tres emiten votos concurrentes y cinco emiten votos disidentes. Parece que, en este caso, será jurisprudencia vinculante aquello que sólo avalan tres de los once ministros, lo cual es claramente una aberración. En Estados Unidos es ampliamente discutido cuál debe ser el valor del precedente de las decisiones plurales. La mayoría de los autores coinciden que una decisión plural lo único que refleja son las distintas posiciones jurídicas al interior del Tribunal y que, como tales, su valor de precedente para futuros litigios es muy débil e incierto. Véase Davis, J. y Reynolds, W., "Judicial Cripples: Plurality Opinions in the Supreme Court", Duke Law Journal, vol. 59, 1974, p. 57 y ss.; Novak, L., "The Precedential Value of Supreme Court Plurality Decisions", Columbia Law Review, vol. 80, 1989, pp. 757 y ss.; Note, "Plurality Decisions and Judicial Decisionmaking”, Harvard Law Review, vol. 94, 1981, pp. 1128 y ss.

4 En Estados Unidos, el equivalente a la jurisprudencia constitucional, son los precedentes constitucionales o el case law constitucional, y en Europa el equivalente es la doctrina constitucional. 
bunal, es decir, en la forma en que éste logra entrelazar las distintas decisiones judiciales, de tal manera que todas ellas, en conjunto, definen el alcance y sentido del derecho en cuestión. ${ }^{5}$

Este proceso concatenado y gradual que sigue la generación de la jurisprudencia constitucional en Estados Unidos y en Europa no existe en México. Como todos sabemos, en México las tesis aisladas y jurisprudenciales se publican en forma separada a las sentencias que les dieron origen. La jurisprudencia constitucional se convierte, por tanto, en un conjunto de criterios jurídicos autónomos e independientes de las sentencias. Ello genera al menos dos problemas importantes: 1) la interpretación constitucional se convierte en una fragmentación de sentidos normativos dados por un número amplio de órganos jurisdiccionales (pleno, salas y colegiados) y, 2) no existen principios comunes que entrelacen las decisiones constitucionales en una misma materia.

Esto último nos lleva al aspecto más distintivo y atípico de la jurisprudencia constitucional en México. Mientras que en Estados Unidos y en Europa la fuerza vinculante de las decisiones constitucionales previas lleva implícita la obligación del juez posterior de darle autoridad a los razonamientos que justifican la decisión, en México no. Dichos razonamientos, en Estados Unidos y Europa, tienen generalmente como telón de fondo los fines que persigue la Constitución, los valores y principios que protege la democracia, la protección del interés público, etcétera. Este tipo de interpretación sustancialista o axiológica de la Constitución requiere de la fuerza vinculante de la doctrina o el case law constitucionales por dos razones. En primer término, porque de esa manera se logra una interpretación coherente e integral de la Constitución; los valores y los principios constitucionales son el eje rector subyacente del entramado normativo de la Constitución; gracias a ellos, la Constitución es una nor-

5 La mejor manera de entender este proceso es analizando una secuencia de decisiones judiciales en específico. Para el caso de la Corte Suprema norteamericana, véase Magaloni, Ana Laura, El precedente constitucional en el sistema judicial norteamericano, Madrid, McGraw-Hill, 2001, pp. 216. Dicho trabajo analiza distintas líneas jurisprudenciales de la Corte Suprema en materia de derechos fundamentales. Véase, sobre todo, pp. 118-137. Para el caso del Tribunal Constitucional español es particularmente ilustrativo el libro coordinado por Rubio Llorente, Francisco, Derechos fundamentales y principios constitucionales, Barcelona, Ariel, 1995. En este trabajo, distintos autores ordenan y sistematizan los pronunciamientos del Tribunal Constitucional español que precisan el contenido de los derechos fundamentales y los principios constitucionales. 
ma integral y coherente. Se puede decir que el conjunto de sus preceptos buscan proteger, de distintas maneras, los valores y principios que caracterizan a una democracia constitucional. El hecho de que los jueces constitucionales estén vinculados a los razonamientos de sus decisiones previas y que, a su vez, estos razonamientos tengan que ver con los valores y principios que subyacen en el entramado normativo, es lo que permite que la Constitución pueda ser leída como lo que es: un cuerpo coherente y articulado de normas.

En segundo término, la interpretación constitucional que se hace cargo de los razonamientos previos, limita el grado de discrecionalidad que tienen los jueces para interpretar los principios y valores que definen a las Constituciones democráticas. Ello es fundamental para la confianza y aceptación de los tribunales constitucionales, pues hace que, a pesar del carácter axiológico de tales decisiones, éstas no parezcan producto de la subjetividad o el capricho de los jueces. En este sentido, el razonamiento concatenado y consistente con las decisiones constitucionales hace que la tendencia "axiologizante" de la jurisdicción constitucional en Europa y en Estados Unidos sea compatible con los presupuestos del Estado de derecho.

En el caso mexicano, la jurisprudencia constitucional - dado que se independiza de la sentencia que le dio origen y que, por tanto, el razonamiento de dicha decisión no lo conoce ni vincula al juez posterior- no puede articular de forma concatenada y consistente el contenido de los principios y valores constitucionales. Una característica que define a nuestra jurisprudencia es que pocas veces se pueden desprender de las mismas interpretaciones constitucionales que se hagan cargo de los valores y principios que protegen la Constitución. Tenemos una jurisprudencia constitucional poco sustantiva o axiológica, lo cual resulta un contrasentido: la norma constitucional es esencialmente una norma que protege los valores que definen a una democracia y, paradójicamente, las tesis aisladas y jurisprudenciales prestan poca atención a dichos valores. Donde más se puede apreciar esta deficiencia de la jurisprudencia mexicana es en la interpretación constitucional de los derechos fundamentales, los cuales, como todos sabemos, tienen una carga valorativa particularmente fuerte en comparación con otros preceptos constitucionales.

Sin duda existen muchas explicaciones a este fenómeno. Sin embargo, lo que queremos destacar sólo es una de ellas: la manera en que en Méxi- 
co se establece y publica la jurisprudencia constitucional hace que lo que exista como parámetro normativo para los jueces sea un conjunto de criterios judiciales dispersos y una desvinculación con los razonamientos que justifican tales criterios. Mientras que ello sea así, los jueces constitucionales enfrentarán grandes problemas para dotar de contenido a los preceptos abiertos y sustanciales de la Constitución. Particularmente, la configuración jurisprudencial de los derechos fundamentales será siempre escueta y poco eficaz para garantizarlos. Para demostrarlo, vamos a analizar, en las siguientes secciones, la eficacia del derecho constitucional a la defensa y su relación con el desarrollo jurisprudencial.

III. EL NIVEL DE EFICIENCIA DEL DERECHO CONSTITUCIONAL

A UNA "DEFENSA ADECUADA" EN LAS AGENCIAS DEL MINISTERIO PÚBLICO Y LOS JUZGADOS PENALES

El derecho del acusado a contar con una defensa adecuada, tanto en la fase de detención como en la del juicio penal, es un derecho instrumental para garantizar que la sanción más severa que puede imponer el Estado, que es la pérdida de la libertad, sea a través de un proceso justo. El derecho a contar con un abogado en la fase de detención es un mecanismo para garantizar al detenido el ejercicio de sus demás derechos constitucionales: el derecho a guardar silencio, el derecho a no ser incomunicado ni torturado, el derecho a no ser sometido a una detención arbitraria, el derecho a ser informado de las razones de la detención, entre otros. El abogado defensor es quien, en último término, puede impedir, a través del ejercicio de los recursos legales conducentes, que estos derechos constitucionales del detenido se violen por la policía y el Ministerio Público, o bien, que sus violaciones tengan consecuencias jurídicas en el proceso.

Asimismo, en la fase del juicio penal, el abogado de la defensa es quien asegura la efectiva realización de los principios de igualdad y contradicción entre las partes, los cuales son principios esenciales para que el juez pueda dictar una sentencia justa. En este sentido, se puede sostener que, cuando el derecho a la defensa no está plenamente garantizado 
en la fase de detención y en el juicio, el proceso a través del cual el juez llega a su veredicto es un proceso viciado de origen. ${ }^{6}$

En el caso de México, el derecho a la defensa está estipulado en el artículo 20, inciso A, fracciones IX y X de la Constitución. Básicamente, dicho artículo señala que el inculpado tiene "derecho a una defensa adecuada, por sí, por abogado o por persona de su confianza. Si no puede o no quiere nombrar a un defensor, después de haber sido requerido para hacerlo, el juez le designará uno de oficio". Según el último párrafo del inciso A del artículo 20 constitucional, este derecho también debe ser observado durante la averiguación previa.

La eficacia del derecho constitucional del acusado a contar con una "defensa adecuada", tanto en la etapa de detención como en el juicio penal, se puede medir de formas distintas. En el caso de las dos encuestas a población en reclusión del CIDE, ${ }^{7}$ lo intentamos hacer de dos maneras. Por un lado, a través de la percepción de los propios sentenciados: cómo evalúan ellos la calidad de la defensa que recibieron a lo largo de todo el proceso, desde la averiguación previa hasta la sentencia. Esta medición puede tener sesgos dado que el acusado fue sentenciado. Por ello, también intentamos medir la calidad de la defensa a través del nivel de eficacia de otros los derechos constitucionales de acusado, asumiendo que una "defensa adecuada" debe por lo menos garantizar que tales derechos no sean violados y que si lo son, ello tenga consecuencias jurídicas en el proceso. Los datos de ambas encuestas revelan la ineficacia del derecho a la defensa en las dos formas de medirlo. A continuación analizaremos los datos más significativos.

\section{La eficacia del derecho a la defensa en las agencias del Ministerio Público}

Lo primero que hay que destacar es que $93 \%$ de los internos fueron detenidos en flagrancia o flagrancia equiparada, lo que indica que ese

6 Al respecto, véase las sentencias del Tribunal Constitucional español 47/1987, $139 / 1987$ y $135 / 1991$.

7 El levantamiento de las encuestas a población en reclusión en el Distrito Federal y el Estado de México, en 2002 y 2005, ha generado diferentes productos académicos. Todos los datos que se citan en el artículo corresponden a los datos publicados en Bergman, Marcelo (coord.), Delincuencia, marginalidad y desempeño institucional, México, CIDE, 2006, p. 83. 
mismo porcentaje pasó 48 horas en una agencia del MP antes de que su asunto fuera consignado ante el juez.

Uno de los datos más relevantes de la encuesta es la baja eficacia del derecho a la defensa en esta fase el proceso: $70 \%$ de los encuestados señalan que no contaron con la asistencia de un abogado. La práctica recurrente en las agencias es que el acusado, en el mejor de los casos, cuenta con el apoyo de un familiar y que, al momento de integrar la averiguación previa, el agente del Ministerio Público le hace firmar como si hubiese ejercido algún tipo de defensa en su carácter de "persona de confianza". Esta práctica recurrente explica, en parte, los altos niveles de arbitrariedad y la ineficacia de los derechos del detenido que prevalecen en las agencias del Ministerio Público. Algunos datos reveladores son los siguientes:

Tabla 1. Porcentaje de eficacia del derecho a la defensa

\begin{tabular}{|l|l|l|}
\hline \multicolumn{1}{|c|}{ Información a los detenidos } & 2002 & 2005 \\
\hline No le explicaron la diferencia entre la fase de acusación y la de juicio & $91 \%$ & $92 \%$ \\
\hline No le informaron de su derecho a no declarar & $80 \%$ & $72 \%$ \\
\hline $\begin{array}{l}\text { No estuvo presente su abogado, o la persona de confianza, cuando rindió } \\
\text { su declaración }\end{array}$ & $70 \%$ & $70 \%$ \\
\hline Se declaró culpable ante el Ministerio Público & $34 \%$ & $28 \%$ \\
\hline No le informaron de su derecho a hacer una llamada telefónica & $72 \%$ & $70 \%$ \\
\hline
\end{tabular}

Como se puede observar en la tabla 1, las respuestas de los internos apuntan mayoritariamente hacia la arbitrariedad. En las agencias del Ministerio Público los derechos constitucionales del detenido son frecuentemente violados y, lo más delicado, ello no tiene consecuencias legales en el proceso. Cabe destacar que, según las normas procesales en materia penal, todas las pruebas que el Ministerio Público recaba en esta fase del proceso tienen valor probatorio en juicio, a pesar de que el juez no verificó que dichas pruebas fuesen recabadas de acuerdo con la ley. En este sentido, la violación frecuente a los derechos del detenido en la agencia del Ministerio Público tiene graves consecuencias en el proceso e inhibe de forma significativa la posibilidad del procesado de tener un juicio justo. 


\section{La eficiencia de la defensa en el juicio penal}

En el juicio penal, la práctica común es que el juez designe a un defensor de oficio, cuando el acusado no puede contratar a un abogado privado. Ello, según los datos de la encuesta, sucede en $73 \%$ de los acusados. Sin embargo, $45 \%$ decide remplazar al abogado de oficio por uno privado a la mitad del juicio; la razón principal del cambio es que, en su opinión, no hizo nada para defenderle. ${ }^{8}$ Lo cual nos habla de lo que todo el mundo sabe: la defensoría pública, en el ámbito de la justicia penal local, es una de las instituciones más abandonadas del país. Nosotros creemos que se debe, en parte, a que los jueces constitucionales no han dotado de contenido sustantivo al derecho a una defensa adecuada. Es decir, la ausencia de verdaderos defensores públicos no tiene ningún costo para nadie: los ministerios públicos continúan ganando juicios y las sentencias de los jueces no son revocadas por ese motivo. ¿Por qué mejorar la calidad de la defensa pública?

Ahora bien, el hecho de que el juez se asegure que el acusado cuenta con un defensor, sea público o privado, no significa que el defensor lleve a cabo una "defensa adecuada" como lo estipula la Constitución. Por ejemplo, $32 \%$ de los encuestados afirman que el defensor no estuvo presente al momento de rendir su declaración. Por lo que conocemos de las prácticas en los juzgados penales, el defensor público muchas veces está atendiendo varias audiencias en forma simultánea. Por lo tanto, es posible que no esté presente al momento en que el acusado rinda su declaración, pero que firme las constancias de autos como si hubiese estado presente. Nuevamente, la única manera en que estas prácticas terminen es dotando de contenido sustantivo al derecho a una "defensa adecuada". Si se supone que estuvo presente el defensor, pero no hizo nada para defender al acusado, el derecho a la defensa debería estimarse violado.

Otra práctica recurrente en los juzgados penales es que el defensor, principalmente el público, no se entrevista con el acusado en privado antes de rendir su declaración, ni previamente a las audiencias. Los datos de la Segunda Encuesta a Población en Reclusión constatan esta práctica:

8 Según datos de la Consejería Jurídica y de Servicios Legales del Distrito Federal, se cuenta con sólo 318 defensores de oficio, y en 2006 atendieron 46,816 casos en las materias penal, familiar y civil. 
$64 \%$ de los internos no se entrevistó con su abogado antes de rendir su declaración preparatoria.

En cuanto a la calidad de la defensa, entendida como las actuaciones de los defensores, los datos de la encuesta revelan que $60 \%$ de los internos no fue asesorado por su abogado antes de las audiencias y que $48 \%$ ni siquiera su abogado le explicaba lo que estaba sucediendo en las mismas. Esta baja calidad de la defensa muy posiblemente está correlacionada con los defensores públicos.

Ello lo sugieren algunos datos de la encuesta de 2005. Cuando se les pregunta a los internos sobre su percepción respecto de la actuación de su abogado, $57 \%$ responde que se sintió poco o nada defendido. Sin embargo, cuando se diferencia esta percepción entre abogados públicos y privados, los públicos son mucho peor calificados. Ello se observa en la siguiente gráfica:

Gráfica 1. Perecepción de los detenidos sobre la actuación de su abogado

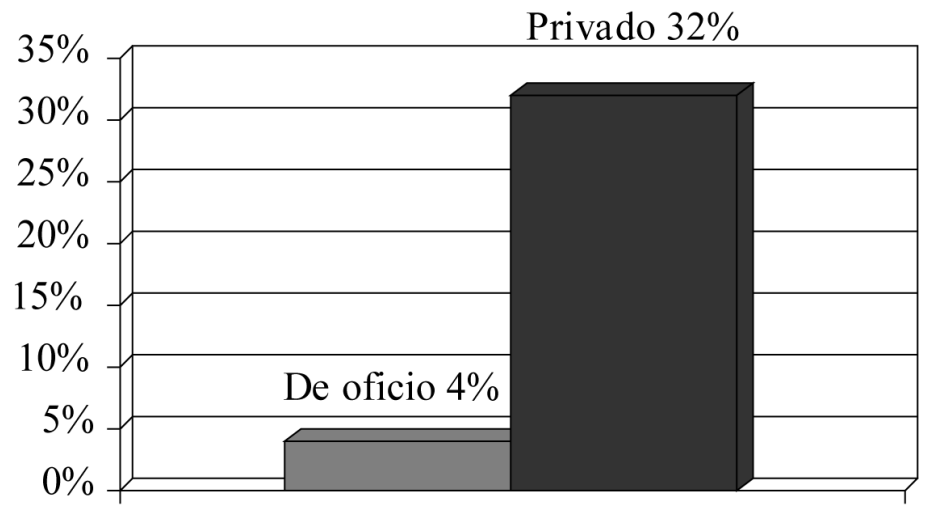

Creen que su abogado se esforzó mucho en defenderlos

En suma, los datos revelan una grave ineficacia del derecho constitucional a una "defensa adecuada". En la fase de detención en las agencias del Ministerio Público la defensa legal es prácticamente inexistente. Los detenidos, en su inmensa mayoría, son incomunicados, no se les informa cuáles son sus derechos, ni mucho menos se les permite ejercerlos. La figura de "persona de confianza" se ha convertido en un simulacro del de- 
recho a la defensa. Por lo que toca a la fase de juicio, los jueces penales se aseguran que exista, nominalmente, un defensor; sin embargo, en la práctica, este defensor hace poco por efectivamente defender al procesado. La sola presencia del defensor - la cual también puede ser simulada en el expediente - no asegura en absoluto que el acusado tenga una "defensa adecuada" como lo establece la Constitución.

La pregunta central a resolver es por qué ello puede suceder sin que tenga ninguna consecuencia jurídica en el proceso. La respuesta a esta interrogante se encuentra en la configuración jurisprudencial del derecho a una "defensa adecuada" que han llevado a cabo la Corte y los tribunales colegiados de circuito. En el siguiente apartado analizaremos este tópico.

\section{EL DESARROLLO JURISPRUDENCIAL DEL DERECHO A UNA DEFENSA ADECUADA}

Para analizar la forma en que la Suprema Corte y los tribunales colegiados han interpretado y desarrollado el derecho constitucional del inculpado a contar con una defensa adecuada, vamos a analizar las tesis aisladas y jurisprudenciales de la Novena Época. El hecho de centrar nuestro estudio sólo en la Novena Época tiene una clara justificación. La Novena Época comienza con la reforma constitucional de 1994. Como todos sabemos, dicha reforma pretende configurar una jurisdicción constitucional acorde con las nuevas coordenadas democráticas del país. Para ello se reconfigura la Suprema Corte de Justicia, se nombran nuevos ministros y se amplía el ámbito jurisdiccional de la Corte. Asimismo, con dicha reforma se buscó garantizar la independencia de los jueces federales instaurando el sistema de carrera judicial a cargo de un órgano distinto de la Corte: el Consejo de la Judicatura Federal. Nosotros creemos que esta reforma es un especie de acto "refundacional" de la jurisdicción constitucional mexicana, que pretende marcar la diferencia entre dos sistema políticos distintos. Uno esperaría, por tanto, es que los criterios de interpretación constitucional de la Novena Época se diferenciaran sustantivamente de los viejos criterios generados en un contexto político autoritario. En este sentido, estudiar la Novena Época significa analizar hasta qué punto los jueces constitucionales han transformado su función y su papel en concordancia con los cambios políticos del país. 
El análisis de las tesis aisladas y jurisprudenciales con respecto al derecho una defensa adecuada lo vamos a llevar a cabo de dos maneras. En primer término, vamos a clasificar las tesis por los distintos temas o problemas que abordan y vamos a hacer un análisis cuantitativo de las mismas, es decir, presentaremos el porcentaje de tesis que abordan cada tema y el porcentaje de éstas que fueron emitidas por el Pleno, las salas y los tribunales colegiados. En segundo término, vamos a realizar un análisis cualitativo de las tesis de referencia, analizando los contenidos específicos de cada uno de los temas o problemas en los que clasificamos las tesis de referencia.

\section{Análisis cuantitativo de las tesis aisladas y jurisprudenciales del derecho constitucional a una defensa adecuada}

Para poder seleccionar las tesis objeto de nuestro estudio, llevamos a cabo una búsqueda en el sistema IUS con la palabra "defensor", tanto en el rubro como el texto. Como resultado de esta búsqueda se encontraron 286 tesis (aisladas y jurisprudenciales), de las cuales sólo 91 (32\%) hacen referencia al derecho constitucional de la defensa adecuada del artículo 20 fracciones IX y X. De ahí que nuestro estudio se concentre en el análisis y sistematización de esas 91 tesis. ${ }^{9}$ La tabla siguiente muestra la clasificación por temas y justificación de esas tesis, así como el número y porcentaje correspondientes a tesis aisladas o jurisprudenciales.

9 Los 286 criterios resultantes de la búsqueda se clasificaron como sigue. En primer lugar, se seleccionaron aquellas tesis en los que aparece el término de defensor, pero no se hace referencia al derecho constitucional establecido por el artículo 20 fracción IX y X (153 tesis aisladas y 30 jurisprudenciales). En el anexo 1, se puede consultar el agregado de jurisprudencias que se dejaron fuera del análisis por no tener relevancia con el derecho constitucional a una defensa adecuada. Dentro de ese grupo de tesis, encontramos que 108 (de las cuales sólo 21 son jurisprudenciales) se refieren a aquella diversidad de actos procesales en el que el defensor actúa en nombre del inculpado (i. e. el inculpado o su defensor pueden interponer el recurso de apelación), o bien, aquellos actos en donde el defensor no puede actuar en nombre del inculpado. Dado que ello no tiene que ver propiamente con el derecho a una defensa adecuada, eliminamos a esas tesis de nuestro análisis. 
Tabla 2. Tesis aisladas y jurisprudenciales del derecho constitucional a una defensa adecuada

\begin{tabular}{|c|c|c|c|c|}
\hline Tema & Justificación & $\begin{array}{c}\text { Tesis } \\
\text { Aisladas }\end{array}$ & $\begin{array}{c}\text { Tesis } \\
\text { Jurisprudenciales }\end{array}$ & Total \\
\hline Presencia & $\begin{array}{l}\text { El defensor debe estar presente } \\
\text { en las audiencias en las diferen- } \\
\text { tes etapas procesales. }\end{array}$ & $\begin{array}{c}35 \\
60 \%\end{array}$ & $\begin{array}{c}22 \\
67 \%\end{array}$ & $\begin{array}{c}57 \\
63 \%\end{array}$ \\
\hline $\begin{array}{l}\text { Cuándo pro- } \\
\text { cede la desig- } \\
\text { nación del } \\
\text { defensor de } \\
\text { oficio }\end{array}$ & $\begin{array}{l}\text { Cuando puede o debe ser desig- } \\
\text { nado el defensor de oficio. }\end{array}$ & $\begin{array}{c}15 \\
26 \%\end{array}$ & $\begin{array}{c}4 \\
12 \%\end{array}$ & $\begin{array}{c}19 \\
21 \%\end{array}$ \\
\hline $\begin{array}{l}\text { Quién puede } \\
\text { ser defensor }\end{array}$ & $\begin{array}{l}\text { Se refiere a las características } \\
\text { que debe reunir el defensor para } \\
\text { poder fungir como tal. }\end{array}$ & $\begin{array}{c}3 \\
5 \%\end{array}$ & $\begin{array}{c}6 \\
18 \%\end{array}$ & $\begin{array}{c}9 \\
9 \%\end{array}$ \\
\hline $\begin{array}{l}\text { Negligencia } \\
\text { del defensor }\end{array}$ & $\begin{array}{l}\text { Cuando se configura la negli- } \\
\text { gencia del defensor. }\end{array}$ & $\begin{array}{c}2 \\
3.4 \% \\
\end{array}$ & $\begin{array}{c}0 \\
0 \% \\
\end{array}$ & $\begin{array}{c}2 \\
1.9 \% \\
\end{array}$ \\
\hline $\begin{array}{l}\text { Cambio de } \\
\text { defensores }\end{array}$ & $\begin{array}{l}\text { Se viola la garantía constitucio- } \\
\text { nal del artículo } 20 \text { fracción IX si } \\
\text { se cambia de defensor continua- } \\
\text { mente. }\end{array}$ & $\begin{array}{c}2 \\
3.4 \%\end{array}$ & $\begin{array}{c}0 \\
0 \%\end{array}$ & $\begin{array}{c}2 \\
2 \%\end{array}$ \\
\hline $\begin{array}{l}\text { Conflicto de } \\
\text { intereses }\end{array}$ & $\begin{array}{l}\text { Cuando existe un conflicto de } \\
\text { interés para el abogado. }\end{array}$ & $\begin{array}{c}1 \\
1.7 \% \\
\end{array}$ & $\begin{array}{c}0 \\
0 \% \\
\end{array}$ & $\begin{array}{c}1 \\
1 \% \\
\end{array}$ \\
\hline $\begin{array}{l}\text { E1 derecho } \\
\text { constitucional } \\
\text { del inculpado } \\
\text { va más allá de } \\
\text { la presencia } \\
\text { del defensor }\end{array}$ & $\begin{array}{l}\text { Explica el derecho constitucio- } \\
\text { nal del inculpado a contar con } \\
\text { defensor más allá del derecho a } \\
\text { tener un defensor. }\end{array}$ & $\begin{array}{c}0 \\
0 \%\end{array}$ & $\begin{array}{c}1 \\
3 \%\end{array}$ & $\begin{array}{c}1 \\
1 \%\end{array}$ \\
\hline Total & & $\begin{array}{c}58 \\
100 \% \\
\end{array}$ & $\begin{array}{c}33 \\
100 \%\end{array}$ & $\begin{array}{c}91 \\
100 \%\end{array}$ \\
\hline
\end{tabular}

Como se puede observar, los tres primeros rubros de nuestra clasificación se refieren a aspectos formales de la defensa: cuándo procede la designación, en dónde debe estar presente el defensor, quién puede fungir como tal, etcétera. Noventa y tres por ciento de las tesis se agrupan en estos tres rubros y, particularmente, se concentran en el rubro de presencia del defensor (63\%). Ello es un primer indicador de que, para los tribunales federales, el sentido constitucional de una defensa adecuada se 
limita, prácticamente, a asegurar la presencia del defensor, pero no la calidad de la defensa.

Los otros rubros de nuestra clasificación, donde sólo existen seis tesis, de las cuales solamente una es jurisprudencial, parecerían, por su denominación, tesis más sustantivas. Sin embargo, como se verá más adelante, ello no es el caso.

Por lo que toca los órganos jurisdiccionales que establecieron las tesis objeto de nuestro estudio, la siguiente tabla presenta un desagregado sobre qué órgano jurisdiccional (Suprema Corte o tribunal colegiado) estableció las tesis aisladas y jurisprudenciales en los diferentes temas en que las hemos clasificado.

Tabla 3. Órgano jurisdiccional que estableció la tesis

\begin{tabular}{|c|c|c|c|c|c|c|}
\hline \multirow[b]{2}{*}{ Tema } & \multicolumn{3}{|c|}{$\begin{array}{c}\text { Total de tesis } \\
\text { (aisladas y jurispruden- } \\
\text { ciales) }\end{array}$} & \multicolumn{3}{|c|}{ Tesis jurisprudenciales } \\
\hline & $\begin{array}{c}\text { Primera } \\
\text { Sala }\end{array}$ & Otros & $T C C$ & $\begin{array}{l}\text { Primera } \\
\text { Sala }\end{array}$ & Pleno & $T C C$ \\
\hline Presencia & 10 & 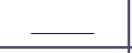 & 47 & 7 & $\underline{-}$ & 15 \\
\hline Quién puede ser defensor & 0 & $\bar{\tau}$ & 3 & 1 & $\begin{array}{c}\text { Pleno } \\
2\end{array}$ & 3 \\
\hline $\begin{array}{l}\text { Cuándo procede la designación } \\
\text { del defensor de oficio }\end{array}$ & 1 & $\begin{array}{c}\text { Segunda } \\
\text { Sala: } \\
1 \\
\end{array}$ & 17 & 0 & - & 4 \\
\hline Cambio de defensores & 0 & 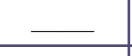 & 2 & 0 & 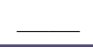 & 0 \\
\hline Conflicto de intereses & 0 & - & 1 & 0 & $\underline{-}$ & 0 \\
\hline $\begin{array}{l}\text { La adecuada defensa no sólo es } \\
\text { tener defensor }\end{array}$ & 1 & - & 0 & 1 & - & 0 \\
\hline Total & 13 & 1 & 53 & 9 & 2 & 21 \\
\hline
\end{tabular}

Como se puede observar, la inmensa mayoría de las tesis fueron emitidas por los tribunales colegiados. Ello es así pues, como todos sabemos, son los tribunales colegiados los que resuelven los amparos directos en materia penal y es en la jurisdicción penal local en donde se concentra el grueso de la actividad jurisdiccional en esa materia. Según los datos de la Secretaría de Seguridad Pública Federal, 95\% de los delitos que se denuncian en el país son locales. Sin embargo, ello no justifica que la Su- 
prema Corte no desarrolle a través de su jurisprudencia el contenido de los derechos del inculpado. Su amplia facultad de atracción se lo permitiría sin problemas. Sólo 11 tesis jurisprudenciales $(31.6 \%$ del total) las emitió la Primera Sala, de las cuales dos fueron resueltas por amparo en revisión y el resto por contradicción de tesis entre tribunales colegiados.

En suma, el análisis cuantitativo de las tesis aisladas y jurisprudenciales del derecho constitucional a una defensa adecuada indican, por un lado, que la mayor parte de dichas tesis se concentra en aspectos formales y no sustantivos del derecho en cuestión, como son la presencia del defensor en las diferentes fases procesales, cuándo procede la designación del defensor público, quién puede ser defensor, etcétera. Por otro lado, el desarrollo jurisprudencial del derecho a la defensa está principalmente a cargo de los tribunales colegiados; la intervención de la Corte tiene que ver, principalmente, con resoluciones de la Primera Sala que resuelven contradicciones de tesis entre colegiados. En el siguiente apartado analizaremos de forma cualitativa las tesis aisladas y jurisprudenciales en cuestión.

\section{Análisis cualitativo de las tesis aisladas y jurisprudenciales} del derecho constitucional a una defensa adecuada

En este apartado se detallará en forma cualitativa el contenido más relevante de las tesis a partir de la clasificación con las que las hemos organizado.

\section{A. Presencia del defensor en las distintas fases procesales}

La presencia del defensor en las diferentes etapas del proceso es un asunto sumamente reiterativo en la jurisprudencia constitucional mexicana. ${ }^{10}$ Como señalamos en el apartado anterior, $67 \%$ de las tesis aisladas y jurisprudenciales hacen referencia a este tema. Estas tesis se pueden clasificar en los siguientes tres momentos procesales: Ministerio Público, juzgado penal y segunda instancia. La tabla 4 muestra el número y porcentaje en función del momento procesal al que se refieren.

10 Los tribunales colegiados más activos en la producción de criterios respecto a la presencia del defensor son el de primer circuito, donde se establecieron seis criterios; el de segundo circuito, con cinco criterios en el tema, y el tercero y el quinto, con cuatro cada uno. 
Tabla 4. Presencia del defensor

\begin{tabular}{|l|c|c|}
\hline \multicolumn{1}{|c|}{ Instancia } & Aisladas & Jurisprudenciales \\
\hline Ministerio Público & 17 & 7 \\
& $48.6 \%$ & $31.8 \%$ \\
\hline Juicio & 10 & 1 \\
& $28.6 \%$ & $4.5 \%$ \\
\hline Segunda instancia & 6 & 14 \\
& $17.1 \%$ & $63.6 \%$ \\
\hline Presencia en procedimientos & 2 & 0 \\
especiales & $5.7 \%$ & $0 \%$ \\
\hline Total & 35 & 22 \\
& $100 \%$ & $100 \%$ \\
\hline
\end{tabular}

a. El defensor en la averiguación previa

Resulta llamativo que casi la mitad de las tesis aisladas y poco más de una tercera parte las tesis jurisprudenciales se concentren en la presencia del defensor en el Ministerio Público, ya que, como analizamos con anterioridad, los datos de las encuestas a población en reclusión del CIDE demuestran que es precisamente en esta fase cuando más ausente está el defensor. Ello se puede explicar, en parte, a que las tesis aisladas y jurisprudenciales que abordan este tema hacen indistinta la asistencia del abogado o de la persona de confianza, basta con que uno de los dos esté presente para que se estime que el derecho a la defensa ha sido garantizado.

Sin lugar a dudas, el texto constitucional no es muy afortunado al permitir que el inculpado pueda ser defendido por persona de confianza y no por un abogado. Sin embargo, los jueces constitucionales podrían resolver los problemas que se derivan de ello a través de la interpretación sustantiva del concepto de "defensa adecuada" a la que se refiere la fracción IX del artículo 20 constitucional. Si la persona de confianza, como sucede en la práctica, no ejerce una "defensa adecuada", entonces se debería estimar que el derecho constitucional a la defensa ha sido violentado. Una interpretación constitucional en este sentido evitaría que, en la agencia del MP, el detenido sólo sea "defendido" por un pariente o un amigo cercano.

Sin embargo, la propia Suprema Corte, en los escasos dos asuntos que ha resuelto el pleno en esta materia, ha reforzado la equivocada equipara- 
ción de la persona de confianza y el abogado defensor. En palabras del máximo tribunal: "una defensa adecuada no sólo la pueden ejercitar los profesionales del derecho, sino también diversos ciudadanos, que sin tener la calidad de abogados, debido a sus nexos de amistad o de parentesco con el inculpado, poseen mayor interés personal para ayudarlo y protegerlo". De ahí que la Corte concluya que, la interpretación del artículo 20, fracción IX de la Constitución, al permitir la defensa a una persona de confianza lo que está garantizándole al inculpado es "una facultad amplísima para designar a la persona o personas que se encarguen de los actos de defensa". ${ }^{11}$ De esta manera, queda vacío de contenido la verdadera garantía constitucional: contar con una defensa adecuada. ¿Cómo va a llevar a cabo una defensa adecuada una persona que no es abogado?

Contrariamente a lo que ha estimado el Pleno, resulta de especial interés la reciente tesis jurisprudencial de la Primera Sala, en donde los ministros comienzan a insertar algunos elementos novedosos. En la tesis jurisprudencial 1a./J. 23/2006, determinó que, la asistencia del defensor, al momento en que el acusado declara ante el Ministerio Público, "no sólo debe estar relacionada con la presencia física del defensor ante o en la actuación de la autoridad ministerial, sino que la misma debe interpretarse en el sentido de que la persona que es puesta a disposición de la autoridad ministerial cuente con la ayuda efectiva del asesor legal". ${ }^{12}$

El problema que tiene esta tesis es que no dice nada respecto de las otras tesis jurisprudenciales, inclusive el propio Pleno, en donde se dispone que la persona de confianza puede fungir como defensor y no se requiere, además, que exista un abogado, por tanto, no va a tener impacto para modificar las prácticas autoritarias que prevalecen en las agencias del Ministerio Público en esta materia.

b. El defensor en el juicio de primera instancia

El número de tesis que se refieren al derecho a la defensa en el juicio de primera instancia es comparativamente mucho menor que en las otras dos fases del proceso (averiguación previa y segunda instancia). Ello es

11 Tesis jurisprudencial, P. LI/2000, Novena Época; pleno, Seminario Judicial de la Federación y su Gaceta, XI, abril de 2000, p. 70.

12 Tesis jurisprudencial, 1a./J. 23/2006, Novena Época; primera sala, Seminario Judicial de la Federación y su Gaceta, XXIII, mayo de 2006, p. 133. 
curioso, pues es en la primera instancia en donde el defensor tiene el papel más importante y la mayor carga de trabajo para defender al acusado. Por tanto, uno esperaría ver en este ámbito el mayor desarrollo jurisprudencial en la materia.

En efecto, como todos sabemos, el juicio se instruye en primera instancia. Es en la etapa de instrucción cuando el abogado de la defensa puede ofrecer y desahogar las pruebas que favorecen a su defendido. Asimismo, es donde tiene la oportunidad procesal para contrainterrogar a los testigos de cargo. Si el acusado no tiene una defensa adecuada en esta etapa del proceso, las principales pruebas en el expediente serán las que el Ministerio Público integra, sin la supervisión del juez, durante la averiguación previa.

En este sentido, sin una defensa adecuada en el juicio de primera instancia, los principios procesales de igualdad y contradicción serán completamente inoperativos y, por tanto, la posibilidad de que el juez dicte una sentencia justa será también altamente improbable.

Las tesis aisladas y jurisprudenciales que se refieren al defensor durante el juicio de primera instancia son 11, de las cuales sólo una es jurisprudencia. Este escaso desarrollo jurisprudencial del derecho a la defensa indica que los amparos directos que llegan a los tribunales colegiados no están planteando la vulneración a este derecho, a pesar de que, como ya señalamos, la evidencia empírica demuestra que el derecho a la defensa es frecuentemente vulnerado durante el juicio.

Todo parece indicar que estamos ante un problema circular: como el acusado no tiene un buen abogado que lo defienda, tampoco tiene la posibilidad de demandar, a través del amparo, la violación a ese derecho. La forma de resolver este círculo vicioso es que los tribunales colegiados estuviesen dispuestos a hacer uso de la amplia suplencia de la queja que existe en el amparo penal y la Corte ejerciera su amplia facultad de atracción para así analizar de oficio los problemas relativos a la calidad de la defensa en el juicio. De esta manera, dichos tribunales podrían establecer una serie de criterios jurisprudenciales que generaran incentivos para que el juez de primera instancia no se conformase, como hasta ahora, con que el defensor esté presente sin hacer nada, o bien, que simplemente simule su presencia firmando las constancias de autos.

Sin embargo, las pocas tesis que existen en esta materia indican que la Corte y los tribunales colegiados no han ni siquiera detectado el proble- 
ma, ¿cómo entonces podrían idear alguna solución? Nuevamente en esta fase del proceso nos encontramos ante un conjunto de tesis formalistas y repetitivas, que lo único que vienen a intentar garantizar es que el abogado de la defensa esté presente en las distintas diligencias procesales.

En efecto, de las 11 tesis relativas a la defensa en el juicio de primera instancia todas, salvo una de ellas, circunscriben el derecho a la defensa a lo que literalmente establece la fracción IX del artículo 20: el inculpado "tendrá derecho a que su defensor comparezca en todos los actos del proceso". Estas tesis entienden que "comparecer" es el equivalente a "estar presente físicamente". Su contenido se limita a definir los distintos actos procesales en donde se requiere su presencia: declaración preparatoria, careos, audiencias de ofrecimiento y de desahogo de pruebas, audiencia de vista, etcétera. De no estar presente el abogado de la defensa en alguna de esas diligencias, las tesis estipulan que se requerirá su reposición. ${ }^{13}$

La única tesis, jurisprudencial, que busca alejarse de esta interpretación formalista y literal de la Constitución, es la XI.2o. J/11 del Segundo Tribunal Colegiado del Décimo Primer Circuito. ${ }^{14}$ En ella, el tribunal acertadamente distingue entre la presencia física del defensor y los actos procesales de defensa. Además establece que estos últimos son los que

13 Las siguientes son las tesis encontradas ordenadas por tipo de diligencia. En careos se encontraron las tesis: XXIII.10.28 P, Novena Época, tribunales colegiados de circuito, Semanario Judicial de la Federación y su Gaceta, t. XXIII, mayo de 2006 y la III.2o.P.71 P, Novena Época, tribunales colegiados de circuito, Semanario Judicial de la Federación y su Gaceta, XIII, abril de 2001; la primera establece que los careos deben ser desahogados con la presencia del defensor, y la segunda estipula lo contrario, que la inasistencia del defensor no se traduce en una violación que amerite su reposición. En la declaración preparatoria se encontraron las tesis: IX.2o.34 P, Novena Época, tribunales colegiados de circuito, Semanario Judicial de la Federación y su Gaceta, XX, julio de 2004, p. 1711; III.2o.P.80 P, Novena Época, tribunales colegiados de circuito, Semanario Judicial de la Federación y su Gaceta, t. XVI, octubre de 2002, p. 1357; y la II.1o.P.143 P, Novena Época, tribunales colegiados de circuito, Semanario Judicial de la Federación y su Gaceta, t. XXIII, enero de 2006, p. 2353; las cuales de manera genérica estipulan que el defensor debe estar presente al momento en que el inculpado hace la declaración. Por último, en cuanto otras diligencias se deduce del contenido de las tesis que el defensor debe estar presente, por ejemplo en la XII.2o.13 P, Novena Época, tribunales colegiados de circuito, Semanario Judicial de la Federación y su Gaceta, t. VI, diciembre de 1997, p. 657, se establece que es necesaria, entre otras firmas, la del defensor, ya que de no reunir esas formalidades la diligencia en cuestión carecerá de valor probatorio.

14 Tesis XI.2o. J/11 del Segundo Tribunal Colegiado del Décimo Primer Circuito, Semanario Judicial de la Federación y su Gaceta, t. VII, febrero de 1998, p. 46. 
garantizan el derecho del inculpado a contar con una defensa adecuada. Dicho de otra manera, no basta con la presencia del defensor en las distintas diligencias procesales. Para que se considere garantizado el artículo 20, fracción IX de la Constitución, la comparecencia del defensor debe "traducirse en actos procesales que revelen una asistencia técnica profesional hacia el inculpado". ${ }^{15}$

¿Cómo podrían evaluar los jueces vinculados a esta jurisprudencia hasta qué punto los actos procesales de la defensa revelan una "asistencia técnica profesional hacia el inculpado"? Para ir dotando de contenido a este estándar que estableció el Segundo Tribunal Colegiado del Décimo Primer Circuito, se requeriría de un proceso casuístico, concatenado y consistente de decisiones posteriores. Ello permitiría que, a partir de las circunstancias de fácticas de cada caso, el tribunal fuese definiendo qué características tienen los actos procesales que son propios de una "asistencia técnica profesional" y cuándo y en qué circunstancias se estima que no satisfacen dicho estándar de asistencia legal. ${ }^{16}$

15 De manera textual la tesis jurisprudencial distingue entre la presencia física y los actos de defensa de la siguiente manera: "Debiéndose aclarar que en lo que corresponde al defensor, la comparecencia a que se contrae la ley no se refiere propiamente a su presencia física en el tribunal el día de la audiencia, sino que aquélla debe traducirse en actos procesales que revelen una asistencia técnica profesional hacia el inculpado, que bien puede ser de manera verbal o por escrito, con tal de que sus alegaciones queden plasmadas al momento de celebrarse dicha audiencia y deban ser tomadas en cuenta al dictarse el fallo respectivo".

16 En Estados Unidos ha existido un prolijo debate académico en torno a la distinta manera que se va desarrollando la jurisprudencia constitucional en función de si el Tribunal Supremo establece un precedente en forma de estándar o en forma de regla. El viejo debate entre Holmes y Cardozo a este respecto es muy conocido. Este debate surge en torno a cómo determinar la responsabilidad civil de las compañías ferroviarias en caso de accidentes en donde el conductor del coche se encontraba en un cruce por donde pasaba el tren. Holmes proponía una regla: el conductor debe parar el auto y ver, mientras que Cardozo proponía un estándar: el conductor debe actuar con razonable precaución. La diferencia central entre ambos tipos de holdings radica en la manera en que se concretiza cada uno de ellos en la resolución de controversias análogas o similares. Una regla busca limitar los juicios de valor y el ámbito de discrecionalidad de los jueces posteriores. En cambio, en el caso de los estándares, el tribunal que establece el precedente busca conferir un amplio margen de libertad para que el tribunal posterior, a la luz de las circunstancias fácticas del nuevo caso que resuelve, decida cómo ajustar su decisión al precedente que le vincula. El proceso concatenado de decisiones judiciales que desarrollan una línea jurisprudencial opera de distinta manera tratándose de reglas o estándares. Está claro que 
Sin embargo, el hecho de que en el caso mexicano la jurisprudencia constitucional no se desarrolle en forma concatenada como sucede en Estados Unidos y en Europa, hace que, en la práctica, un criterio jurisprudencial sustancialista y prometedor como el de este Tribunal Colegiado sea difícil de aplicar y operar en términos jurisdiccionales. La fragmentación de sentidos normativos que provoca la manera en que se establece y utiliza la jurisprudencia constitucional en México tiene, entre otras consecuencias negativas, la imposibilidad de configurar líneas jurisprudenciales que concreticen o expliciten la manera como los preceptos materiales de la Constitución pueden tener impacto real en la forma como los jueces en general interpretan el derecho y resuelven casos concretos. En franco contraste, las tesis textualistas y formalistas, que por su propio contenido no necesitan de un desarrollo jurisprudencial casuístico y concatenado, son fácilmente operables y aplicables por los jueces inferiores. ${ }^{17}$ En este sentido, es más probable que un criterio jurisprudencial formalista tenga mayor impacto en las decisiones judiciales posteriores que uno sustancialista o axiológico.

Más allá de esta problemática, lo cierto es que el primer problema por atender con relación al desarrollo jurisprudencial de la Constitución es la pobre calidad de las tesis jurisprudenciales. De las 11 tesis que existen con relación a la defensa durante el juicio, 10 de ellas lo único que vienen a garantizar es que el defensor esté presente en las distintas diligencias procesales. Ello de por sí lo establece de forma literal la Constitución. Los jueces constitucionales sirven para dotar de sentido normativo, lo que no es obvio ni se desprende de forma literal del texto constitucional. Tal es el caso de la interpretación de lo que significa el texto constitucional de "defensa adecuada" a que se refiere el artículo 20, fracción IX, de la Constitución. Mientras no se desarrolle el sentido normativo de ese

la tesis jurisprudencial que estamos comentando requeriría de un desarrollo propio de las líneas jurisprudenciales que caracterizan a los estándares. Sobre este tema, véase, entre otros, Magaloni, Ana Laura, El precedente constitucional..., cit., nota 5, pp. 138-148; Schlag, P., "Rules and Standard", Los Angeles Law Review, University of California, vol. 33, 1985, pp. 379 y ss.; Sullivan, K., "The Justices of Rules and Standard”, Harvard Law Review, vol. 106, 1992, pp. 50 y ss.

17 De ahí que, mientras no se modifiquen de fondo los procesos y la forma en que se genera y publica la jurisprudencia en México, va a ser muy difícil para los pocos jueces constitucionales que sí entienden cuál es su función al momento de interpretar la Constitución, que sus tesis tengan impacto en la vida ordinaria de los ciudadanos. 
atributo específico del derecho a la defensa, la mayoría de los procesados, sobre todo los que son "defendidos" por el defensor público, seguirán siendo acusados y juzgados en absoluto estado de indefensión.

\section{c. El defensor en la segunda instancia}

Resulta llamativo que la mayoría de las jurisprudencias en cuanto a la presencia del defensor se concentren en esta etapa: 64\% del total de tesis aisladas y jurisprudenciales para ser exactas. Es llamativo porque, contrariamente a lo que sucede en el juicio de primera instancia, en la segunda instancia el papel principal del defensor no tiene que ver con su presencia física, sino con la elaboración y presentación del escrito de apelación. Es en ese recurso escrito en donde el abogado de la defensa desarrolla los argumentos por los que estima que la decisión del juez de primera instancia no es jurídicamente correcta. Su presencia física en la audiencia de vista, por tanto, no es lo más determinante para que el inculpado sea efectivamente defendido en esta fase del proceso.

Sin embargo, la jurisprudencia en la materia parece establecer todo lo contrario: todas las tesis analizadas se refieren exclusivamente a la presencia del defensor en la audiencia de vista. Si no asiste el defensor a esa audiencia y ésta se lleva a cabo, se debe reponer el procedimiento de segunda instancia. ${ }^{18}$

Las razones que da la propia Primera Sala para que ello sea así son las siguientes: "el objetivo de la audiencia de vista, tanto en primera como en segunda instancia, consiste en que una vez iniciado el debate, realice oralmente la defensa correspondiente... la inobservancia de lo anterior se traduce en una omisión grave de la defensa en perjuicio del sentenciado". ${ }^{19}$ De ahí que la Primera Sala concluya que, si no asiste el abogado de la defensa a la audiencia de vista, el tribunal tendrá que designar al defensor público para que realice esa "defensa" oral en la segunda instancia, de lo contrario se tendrá que reponer el procedimiento de apelación.

18 Véase, por ejemplo, las tesis jurisprudenciales 1a./J. 131/2005, Novena Época, Primera Sala, Semanario Judicial de la Federación y su Gaceta, t. XXII, octubre de 2005, p. 126, y la 1a./J. 19/95, Novena Época, Primera Sala, Semanario Judicial de la Federación y su Gaceta, t. II, diciembre de 1995, p. 269.

19 Tesis jurisprudencial 1a./J. 131/2005, Novena Época, Primera Sala, Semanario Judicial de la Federación y su Gaceta, t. XXII, octubre de 2005, p. 126. 
En nuestra opinión, este criterio tiene varios problemas. En primer término, esa defensa oral a la que se refiere la Primera Sala es bastante irrelevante para el sentido final de la decisión del tribunal de segunda instancia. Lo que cuenta, en esta fase del proceso, son los argumentos del escrito de apelación, no lo que el abogado de la defensa exprese en la audiencia de vista. En segundo término, suponiendo que fuese tan determinante para la defensa dicha audiencia, entonces cómo es que los ministros permiten que, de no asistir el abogado del sentenciado, el tribunal designe en ese momento al defensor público para que lleve la defensa oral en la audiencia respectiva. No se necesita ser experto en la materia para entender que cualquier abogado requiere de un tiempo razonable para analizar el expediente y determinar cuáles son los errores del juez inferior que permitirían revocar y modificar el sentido de su sentencia. La forzosa improvisación que tendrá que llevar a cabo el defensor público para deshogar una audiencia de un caso que no conoce resulta a todas luces violatorio del derecho que los jueces constitucionales intentan proteger. ${ }^{20}$ Finalmente, el problema más serio de esta tesis jurisprudencial son los costos que tiene para el sentenciado: la reposición del procedimiento de segunda instancia por la no comparecencia del abogado de la defensa lo único que provoca en la práctica es dilación en la impartición de justicia. Sería muy interesante medir empíricamente el porcentaje de reposiciones del procedimiento de segunda instancia producto de la ausencia del defensor en la audiencia de vista que tienen como consecuencia el cambio de sentido de la sentencia final. Nuestra sospecha es que son tan pocas que resulta completamente contraproducente para los derechos del sentenciado y para la propia eficiencia del aparato judicial la reposición del procedimiento por este motivo.

Este criterio lo estableció la Corte en 2005. Sin embargo, un año después, el Primer Tribunal Colegiado en Materia Penal del Segundo Cir-

20 En el caso mexicano, es particularmente complejo analizar un expediente penal. En primer término, existe una cantidad de papel innecesario en el que muy rápido el lector puede perder los detalles del expediente y los problemas jurídicos sustantivos del mismo. Además, un abogado en segunda instancia no sólo debe revisar con cuidado toda la averiguación previa, sino además toda la instrucción del juicio, es decir, las distintas audiencias en donde se ofrecieron y desahogaron pruebas. Finalmente, tiene que leer toda la sentencia del juez de primera instancia, las cuales no se caracterizan por su brevedad. Ello, en un caso relativamente sencillo, puede significar revisar de 300 a 500 fojas, lo cual, por lo menos, le toma a un abogado serio dos días enteros de trabajo. 
cuito, estableció jurisprudencia justamente en el sentido contrario de lo que estableció la Primera Sala. Según la tesis II.1º.P.J/12:

debe considerarse que la inasistencia de la defensa particular a la audiencia de vista en la apelación y la designación oficiosa en dicho acto por parte de la sala del defensor adscrito, implican una limitación a las garantías de audiencia y de defensa... ya que no existe certeza jurídica de que el defensor de oficio haya tenido un plazo suficiente para imponerse de las constancias existentes y estar en aptitud de alegar a favor del inculpado. ${ }^{21}$

Este mismo criterio lo han establecido otros dos tribunales colegia$\operatorname{dos}^{22}$

A pesar de que es mejor, en términos del derecho a la defensa, las tesis jurisprudenciales de los colegiados, de acuerdo con las reglas que rigen la vinculación judicial a la jurisprudencia, la tesis de la Primera Sala es la que debe regir esta cuestión. Su tesis jurisprudencial vincula jurídicamente a todos los tribunales del país. Sin embargo, lo que este caso de contradicción de criterios revela es que habría que estudiar con más cuidado cómo es que varios tribunales colegiados establecieron tesis jurisprudenciales, por reiteración, que frontalmente iba en contra de la jurisprudencia previamente establecida por la Corte. ¿Qué tan frecuente es que esto ocurra? Sin duda, esta es una pregunta clave que deberían buscar responder los ministros, pues ello, de ser una práctica recurrente, revela una Corte con menos poder y autoridad de lo que suponemos. ${ }^{23}$

21 Tesis II. 1o.P.J/12, tribunales colegiados de circuito, Novena Época, Semanario Judicial de la Federación y su Gaceta, t. XXII, junio de 2006, p. 976.

22 Véase tesis XX.2o. J/11, Novena Época, tribunales colegiados de circuito, Semanario Judicial de la Federación y su Gaceta, t. XXII, noviembre de 2005, p. 663; y la tesis XVI.4o. J/6, Novena Época, tribunales colegiados de circuito, Semanario Judicial de la Federación y su Gaceta, t. XVII, enero de 2003, p. 1585.

23 Esta contradicción entre los dos criterios, siendo el de la Primera Sala anterior al del Tribunal Colegiado, puede estar revelando un problema que habría que analizar empíricamente con mucho cuidado. La pregunta a estudiar es: ¿qué tanto siguen los tribunales colegiados la jurisprudencia de la Corte? Dada la bajísima probabilidad de que los ministros revisen amparos directos que sólo tengan por objeto el control constitucional de la aplicación judicial de la ley, es posible que los tribunales colegiados no estén prestando toda la debida atención a la jurisprudencia de la Corte y que estén generando criterios, como el señalado, claramente contradictorios con lo que estableció el máximo tribunal, lo cual sería muy grave para la coherencia y unidad del desarrollo jurisprudencial de la Constitución. 
La regla constitucional que se puede extraer de las jurisprudencias durante esta etapa es que el defensor tiene que estar presente en la audiencia de vista de segunda instancia, ya que de otro modo se tendrá que reponer el procedimiento. Lo que está en duda es si el tribunal de apelación puede designar al defensor de oficio, en caso de que el abogado de la defensa no acuda a la audiencia de vista. La Primera Sala dice que sí, pero los tribunales colegiados no están de acuerdo. Sin embargo, lo verdaderamente relevante es que nada de lo que la Corte o los tribunales colegiados han dicho respecto al derecho a la defensa en la segunda instancia tiene que ver con la parte sustantiva del derecho: qué significa, en términos constitucionales, una defensa real y efectiva.

\section{B. Designación del defensor de oficio}

Ésta es la segunda categoría de nuestra clasificación. En este rubro se encuentran $21 \%$ del total de las tesis aisladas y jurisprudenciales en torno al derecho constitucional a una defensa adecuada. La cuestión constitucional que buscan resolver es ¿cuándo debe proceder la designación del defensor de oficio?

Este conjunto de tesis básicamente vienen a repetir lo que la Constitución establece en forma literal: si el inculpado no manifiesta su voluntad de defenderse por sí solo, o bien, no designa a una persona de confianza o un abogado privado para hacerlo, entonces el Ministerio Público y el juez penal le tendrán que designar a un defensor de oficio. ${ }^{24}$

La Primera Sala de la Corte ha avalado esta manera textual y repetitiva de abordar esta cuestión constitucional. En la tesis jurisprudencial 1a./J.91/200, la Primera Sala repitió lo mismo que venían diciendo los tribunales colegiados:

la fracción IX del artículo 20 de la Constitución... prevé tres formas a través de las cuales el inculpado puede ejercer su defensa, a saber: a) por sí mismo, b) por su abogado, y c) por persona de su confianza; y además, dispone que

24 Véase, por ejemplo, la tesis jurisprudencial XXIII.1o.J/17, Novena Época, tribunales colegiados de circuito, Semanario Judicial de la Federación y su Gaceta, t. XXIII, junio de 2006, p. 976, así como la tesis XXIII.1o. J/15, Novena Época, tribunales colegiados de circuito, Semanario Judicial de la Federación y su Gaceta, t. X, octubre de 1999, p. 1178. 
en caso de que el inculpado no elija una de estas posibilidades, después de que haya sido requerido para ello, el juez deberá nombrarle un defensor. ${ }^{25}$

El problema central de estas tesis es que no se hacen cargo de las prácticas autoritarias que comúnmente se esconden detrás de un proceso penal escrito como el que existe en México. Lo que el inculpado manifieste o deje de manifestar al Ministerio Público o al juez no necesariamente queda registrado en el expediente. Tampoco se puede asegurar que, a pesar de quedar escrito en el expediente, el Ministerio Público en la fase de averiguación previa o el juez en la fase de juicio, le informan al inculpado de los derechos que la Constitución establece a su favor. Por ello, cuándo la autoridad decide designar o no al defensor público es una cuestión que tiene que ver con las prácticas cotidianas en las agencias del Ministerio Público y en los juzgados penales, y no con lo que manifiesta el acusado, como ingenuamente lo han establecido los jueces constitucionales.

En la fase de averiguación previa, la práctica que prevalece, al menos en el Distrito Federal y el Estado de México, es que el Ministerio Público, cuando el detenido no contrata a un abogado privado, opta por la figura de la persona de confianza. Según la Segunda Encuesta a Población en Reclusión, ello acontece en $70 \%$ de los casos. Esta opción no tiene nada que ver con la voluntad del detenido. En esta fase, como ya analizamos, prevalece la incomunicación y la ausencia de toda información respecto de cuáles son sus derechos. El Ministerio Público, por tanto, registrará en el expediente que el detenido "manifestó" su deseo de ser defendido por una persona de confianza, para así evitar que su acusación se caiga en la fase del juicio. Las tesis aisladas y jurisprudenciales no impiden en absoluto que ello continúe sucediendo.

En el juicio, en cambio, la práctica recurrente es que el juez opte por designar al defensor de oficio, cuando el procesado no tiene un abogado privado. Sin embargo, al igual que en la agencia del Ministerio Público, esta opción del juez nada tiene que ver con la voluntad del procesado, opera en forma automática. Las tesis de referencia permiten que así suceda.

25 Tesis 1a./J. 91/2001 de la Primera Sala, Semanario Judicial de la Federación y su Gaceta, t. XIV, noviembre de 2001, p. 9. 


\section{Quién puede ser defensor}

La cuestión constitucional relativa a quién puede fungir como defensor es el tercer rubro más desarrollado por la jurisprudencia en relación con el derecho a una defensa adecuada: $18 \%$ de las tesis aisladas y jurisprudenciales se refieren a esta temática. Estas tesis se pueden organizar en torno a tres problemas: 1) quién puede ser defensor particular, 2) quién puede ser defensor público, y 3 ) quién puede figurar como "defensor" en los casos en que el inculpado confiesa el delito.

Por lo que toca al defensor particular, la Primera Sala ha establecido que la designación del propio acusado de su defensa puede o no recaer en un abogado profesional; la Constitución le da una amplia prerrogativa al inculpado para elegir a cualquier persona que lo defienda. ${ }^{26}$ El Segundo Tribunal Colegiado en materia penal del Segundo Circuito ha hecho, además, una distinción a este respecto entre la fase de averiguación previa y la del juicio. Según dicho tribunal, en la fase de averiguación previa el acusado puede ser defendido por el más amplio abanico de personas. La defensa a cargo de persona de confianza, según el Tribunal Colegiado, "no exige ninguna relación previa de amistad, parentesco o afinidad tal que genere un motivo de posible 'confianza' en el sentido personal". Con tal expresión, según dicho Tribunal, sólo se busca diferenciar la defensa por abogado o por sí mismo del resto de "defensores" que no caigan en esos dos supuestos. La persona de confianza en el sentido constitucional será, por tanto, una categoría residual: todo lo que no entre en las categorías de defensa por sí mismo o por abogado. Además, dicha persona de confianza no tendrá que tener ningún atributo que asegure la calidad de su desempeño en la averiguación previa. ${ }^{27}$

Sin embargo, en la fase de juicio, el mismo Tribunal Colegiado limita la amplitud de opciones para el acusado. En este caso, según el Tribunal, "si la persona designada no es abogado con título profesional registrado, se le requerirá [al procesado] para que designe, además, a quien lo sea, para que asesore técnicamente al defensor no abogado". ${ }^{28}$ ¿Por qué mantener dos criterios tan distintos para la fase de averiguación previa que para la del

26 Véase, tesis 1a./J.91/2002, Primera Sala, Semanario Judicial de la Federación, noviembre de 2001, p. 9.

27 Tesis: II.2o.P.J/19, Semanario Judicial de la Federación, mayo de 2006, p. 1524.

28 Tesis: II.2o.P.J/7, Novena Época, tribunales colegiados de circuito, Semanario Judicial de la Federación y su Gaceta, t. VIII, diciembre de 1998, p. 961. 
juicio? En nuestra opinión, está claro que tal distinción no se justifica: el inculpado siempre tendría que estar asesorado por un abogado.

Por lo que toca a las características del defensor público, todas las tesis vienen a establecer que sólo pueden actuar como tales los abogados con título profesional. Lo más interesante es que las razones que dan para ello parecen perfectamente aplicables para limitar el papel de la defensa a cargo de personas de confianza. En efecto, la Primera Sala ha establecido que el defensor público tiene que ser un abogado, pues ello asegura "a las personas de escasos recursos económicos que durante el desarrollo del proceso al que se encuentran sujetos estén asesorados por profesionales del derecho, por personas con capacidad en la materia que pueden defender con conocimiento jurídico suficiente sus intereses". ${ }^{29}$ ¿Ello no debería ser aplicable en todo caso? ¿Por qué los jueces constitucionales continúan manteniendo tan abierta la opción de defensa a cargo de persona de confianza en agencias del Ministerio Público? Nosotras creemos que ello son resabios de jueces constitucionales que operaron por muchos años en el contexto de un sistema político autoritario.

Finalmente, también parecen resabios de una cultura judicial autoritaria la nula atención que los jueces constitucionales han puesto en quién puede figurar como defensor cuando el inculpado confiesa el delito que se le imputa. En efecto, una excepción constitucional importante en cuanto a la posibilidad de ser defendido por persona de confianza tiene que ver con la confesión del acusado. Según el artículo 20, fracción II de la Constitución, la confesión, sea ante el juez o el Ministerio Público, carecerá de valor probatorio si se produce sin asistencia de su defensor. La interpretación más razonable de este precepto es que en estos casos no es posible que el acusado se defienda por sí sólo o a través de una persona de confianza; requiere forzosamente de una asesoría legal profesional. Una confesión es una prueba extrema, pues significa la renuncia del inculpado a defenderse o a resistir la acusación. Por ello se requiere que dicha confesión se produzca en un contexto de plena libertad, ajeno a todo tipo de coacción verbal o física y con plena conciencia, por parte de quien confiesa, de las consecuencias legales que ello lleva aparejado. ${ }^{30}$

29 Tesis 1a./J.91/2002, Primera Sala, Semanario Judicial de la Federación, noviembre de 2001, p. 9.

30 El texto constitucional vigente fue producto de una reforma constitucional en 1993, cuyo objetivo central fue evitar que los ministerios públicos extrajeran confesiones 
Un abogado es quien, en principio, está en posibilidad de asegurar que todo ello suceda. ${ }^{31}$

Sin embargo, la jurisprudencia constitucional no ha distinguido la persona de confianza del abogado público o privado en caso de que el acusado confiese el delito que se le imputa. Esta distinción sería de especial relevancia en las agencias del Ministerio Público, en donde, como señalamos, prevalece la práctica de que la defensa esté a cargo de una persona de confianza. No obstante, los jueces constitucionales no parecen preocupados por el tema. Las tesis aisladas y jurisprudenciales estipulan que, en caso de que el inculpado confiese en una agencia del Ministerio Público, se tendrá que designar un defensor de oficio sólo cuando el inculpado no haya manifestado su voluntad de defenderse por sí mismo o por persona de confianza. ${ }^{32}$ Resulta desolador constatar lo poco que han hecho los jueces constitucionales para cerrar las puertas a la arbitrariedad con la que ha funcionado la procuración de justicia en México.

\section{Otras}

Un pequeño grupo conformado por seis tesis se dedican a otros temas que no entran dentro de las tres grandes categorías anteriores. En este grupo se encuentran tesis como: el derecho constitucional a una defensa adecuada garantiza al sentenciado la posibilidad de ofrecer pruebas testi-

por medio de tortura y amenazas. Dicha reforma pretendió cerrar las puertas a estas prácticas autoritarias a través del abogado defensor.

31 ¿Qué incentivos puede tener un acusado a confesar? En el caso de las leyes procesales mexicana no nos parece que existe ningún incentivo, ya que ello no reduce la pena ni la necesidad de pasar por todo el proceso penal, de principio a fin. En este sentido, es posible suponer que en México la confesión sólo puede ser producto de un acusado mal informado y sin asesoría legal. Según la Encuesta a Población en Reclusión, 36\% de los detenidos rinden una confesión en la agencia del Ministerio Público. En contraste, por ejemplo, en el derecho procesal penal norteamericano, la confesión del acusado frente al fiscal puede llegar a cambiar la naturaleza de la acusación, reducir su pena y evitarse el juicio. Lo mismo sucede en Chile, en donde el juez de garantías sólo debe verificar en una audiencia oral que la confesión sea producto de la libertad del acusado y de la asesoría de su abogado.

32 Véase, al respecto, tesis XXIII. 1o. J/17, Novena Época, Primer Tribunal Colegiado del vigésimo tercer Circuito, Semanario Judicial de la Federación, octubre de 1999, p. 1172 . 
moniales en segunda instancia; ${ }^{33}$ existe un conflicto de intereses por parte del abogado defensor si en la agencia del Ministerio Público interviene a favor del acusado y en el proceso a favor del ofendido; 34 o bien, el cambio continuo de defensores en el periodo probatorio vulnera el derecho a una defensa adecuada. ${ }^{35}$

Merece una especial mención la tesis aislada de este pequeño grupo número II.2o.P.A.5P. De acuerdo con el Segundo Tribunal Colegiado en materias penal y administrativa del Segundo Circuito, la deficiente actuación del defensor no justifica la reposición del procedimiento. Para dicho Tribunal, la negligencia o torpeza del defensor no justifican dicha reposición, solamente cabe la misma cuando existe una violación manifiesta a las normas que rigen el procedimiento. ${ }^{36}$

Con este criterio se reduce el derecho constitucional a la defensa adecuada a que el inculpado cuente con un abogado que dice ser su defensor, aunque éste no lleve a cabo los actos procesales más elementales del ejercicio de su cargo, ya ni se diga que actué con responsabilidad y profesionalismo. Sin duda, este tipo de criterios nos permiten constatar lo lejos que están nuestros jueces constitucionales de dotar de contenido a los preceptos materiales y los valores que caracterizan a una democracia constitucional. ${ }^{37}$

33 Tesis jurisprudencial 1a./J. 24/96, Novena Época, Primera Sala, Semanario Judicial de la Federación y su Gaceta, t. IV, septiembre de 1996, p. 51.

34 Tesis XVI.1o.5 P, Novena Época, tribunales colegiados de circuito, Semanario Judicial de la Federación y su Gaceta, t. XX, septiembre de 2004, p. 1754.

35 Tesis IV.2o.P.33 P, Novena Época, tribunales colegiados de circuito, Semanario Judicial de la Federación y su Gaceta, t. XXV, enero de 2007, p. 2243.

36 Tesis II.2o.P.A.5 P, Novena Época, tribunales colegiados de circuito, Semanario Judicial de la Federación y su Gaceta, t. II, julio de 1995, p. 270.

37 El tema de la eficacia de los derechos fundamentales del acusado frecuentemente resulta chocante en un contexto de alta criminalidad como la que prevalece en México desde la década de los ochenta. Se piensa que lo primero es lograr que los criminales estén en la cárcel y dejen de delinquir y el tema de los derechos es un asunto que hoy no nos debe preocupar. Ésta es una aproximación muy simplista al problema. Si fuese verdad que la arbitrariedad es un mal necesario para hacer frente al crimen de forma eficaz, en México la tasa de impunidad no sería tan alta $(90 \%$ de los delitos denunciados queda impune). En México, las procuradurías son tan ineficaces como arbitrarias. En este sentido, el tema de los derechos del acusado tiene que verse desde una óptica distinta: la eficacia de tales derechos es lo que eleva el profesionalismo y capacidad para investigar técnicamente los delitos por parte de las procuradurías. Los derechos imponen estándares de calidad al trabajo de ministerios públicos y policías. Ello, en el mediano plazo, au- 


\section{CONCLUSIONES}

A partir del análisis y sistematización de las tesis aisladas y jurisprudenciales de la Novena Época en torno al derecho constitucional del inculpado a contar con una defensa adecuada, podemos concluir que el desarrollo jurisprudencial de este derecho tiene tres problemas centrales, los cuales explican por qué es un derecho tan ineficaz en los procesos penales.

1. La ausencia de criterios de interpretación constitucional que se hagan cargo de la dimensión axiológica o sustantiva del derecho a la defensa.

La Constitución es por definición una norma con un alto contenido axiológico. El conjunto de derechos fundamentales son el núcleo duro de esa dimensión material o sustantiva de la norma fundamental. Por tanto, resulta problemático, en términos de la eficacia de tales derechos, que la jurisprudencia constitucional en México sea tan formalista. Ello es un indicador de que los jueces constitucionales continúan operando bajo la inercia de las conductas judiciales propias de un sistema autoritario.

En efecto, como vimos, la inmensa mayoría de las tesis aisladas y jurisprudenciales con relación al derecho a la defensa tienden a reiterar lo que textualmente establece la Constitución. Ninguno de los criterios constitucionales estudiados se hace cargo de los valores y principios que, en una democracia constitucional, se busca proteger a través del derecho a la defensa en materia penal, como la libertad, los principios procesales de igualdad y contradicción, la justicia misma del proceso, la no indefensión del acusado, la no arbitrariedad de policías, ministerios públicos y jueces, entre otros. Tampoco ninguno de ellos, salvo dos jurisprudencias, busca dotar de significado a los atributos mínimos que conlleva una "de-

menta en forma significativa su capacidad para detectar y acusar a los delincuentes profesionales. Hoy, las procuradurías, dados sus precarios estándares de calidad, solamente logran capturar al eslabón más débil de la cadena delictiva. En la ciudad de México, por ejemplo, en $2005,47 \%$ de la población en reclusión se le sentenció por robo simple sin violencia por montos menores a dos mil pesos. En el caso de México, contrariamente a lo que comúnmente se piensa, ineficiencia y arbitrariedad se correlacionan en forma positiva: a mayor arbitrariedad, mayor ineficiencia. Para un desarrollo específico de este argumento, véase, Magaloni, Ana Laura, Ineficiencia y arbitrariedad en la procuración de justicia: dos caras de la misma moneda, México, CIDE, Documento de Trabajo, 2007, p. 25. 
fensa adecuada". Los jueces constitucionales han ignorado, lisa y llanamente, la parte sustantiva del derecho a la defensa, según lo establece el texto constitucional. La mayor parte de las tesis estudiadas se han abocado a definir aspectos meramente formales que, además, se derivan de forma literal del texto del artículo 20, fracciones IX y X de la Constitución.

Como señalamos, los jueces constitucionales están para definir lo que no es obvio ni se desprende literalmente de los preceptos constitucionales. Sin embargo, este tipo de interpretaciones, que necesariamente tienen que hacer referencia a los valores y principios que subyacen en la Constitución, aún no forma parte de la cultura judicial mexicana. Mientras que ello sea así, es difícil esperar que los jueces constitucionales lleven a cabo una de las funciones más importantes que tienen en una democracia: garantizar, a través del desarrollo jurisprudencial, la plena eficacia de los derechos fundamentales.

2. La inexistencia de un razonamiento concatenado e integral entre las distintas tesis aisladas y jurisprudenciales.

Como señalamos, una de las características que definen la jurisprudencia constitucional en Estados Unidos y Europa es que ninguna decisión permanece aislada. Toda decisión constitucional con valor de precedente forma parte de un cuerpo concatenado de reglas de creación judicial. Este proceso es fundamental para lograr el establecimiento de criterios de interpretación constitucional que se hagan cargo de la dimensión axiológica de la Constitución. El alto grado de indeterminación de los preceptos materiales de la Constitución sólo puede limitarse y concretizarse a lo largo de una serie de decisiones judiciales, en donde cada una de ellas guarde consistencia con el sentido y el razonamiento (axiológico) de las decisiones anteriores. ${ }^{38}$

Este proceso gradual de generación de la jurisprudencia constitucional hace que la discusión en torno al sentido de la Constitución sea una dis-

38 Dworkin hace la analogía con una novela seriatim escrita por distintos autores. Cada decisión judicial — señala el autor - representa un capítulo de la trama de la novela y, como tal, añade algo nuevo a la misma, pero, a la vez, para formar parte de esa novela, el juez debe tomar en cuenta lo que han escrito sus antecesores, es decir, su sentencia tiene que continuar en forma consistente la "historia" de la secuencia de decisiones previas. Dworkin, D., Law's Empire, Cambridge, Massachusetts, Harvard University Press, 1986, pp. 228-232. 
cusión colectiva, que involucra tanto a los jueces del pasado como a los del presente. Además, en términos prácticos, en virtud de la misma, los jueces constitucionales han podido establecer criterios de interpretación que pueden guiar efectivamente las decisiones de los jueces ordinarios. De esta forma, la jurisdicción constitucional logra garantizar la eficacia de los derechos fundamentales y los valores constitucionales en los procesos judiciales ordinarios. Esto último es lo que, a final de cuentas, hace que la Constitución sea una norma eficaz para los ciudadanos comunes y corrientes.

En el caso de México, como vimos, la forma en que se genera y publica la jurisprudencia inhibe por completo este proceso concatenado. Las tesis asiladas y jurisprudenciales se independizan de las sentencias que les dieron origen y, por tanto, operan, en la práctica judicial, de manera autónoma o independiente. En nuestra opinión, ello hace que los pocos criterios constitucionales sustantivos terminen sin tener el impacto deseado. El grado de indeterminación que caracteriza a los criterios sustantivos, en ausencia de un proceso concatenado que vaya limitando dicha indeterminación, hace que sean difíciles de operar por los jueces ordinarios. Además, la fragmentación de sentidos normativos que genera esta manera de utilizar y publicar la jurisprudencia hace posible que coexistan criterios altamente formalistas y criterios sustantivos en torno a una misma cuestión constitucional, sin que ello produzca necesariamente una contradicción de tesis.

Lo anterior nos parece que sucede con las únicas dos tesis jurisprudenciales que se alejan de la aproximación formalista al derecho a la defensa. En estas tesis los jueces constitucionales intentan comenzar a distinguir entre la presencia del defensor y los actos procesales de la defensa. En el caso de la tesis jurisprudencial de la Primera Sala, la cual hace referencia a la defensa en la fase de averiguación previa, establece que el detenido en flagrancia debe contar con "la ayuda efectiva del asesor legal". ${ }^{39} \mathrm{El}$ problema central de esta tesis es que no dice nada respecto de las otras tesis jurisprudenciales, del propio pleno y de los tribunales colegiados, en donde se dispone que las persona de confianza puede fungir como defensor y que no tiene que tener ningún otro atributo más que lo haya designado el acusado. La ausencia de un desarrollo jurisprudencial

39 Tesis jurisprudencial, 1a./J. 23/2006, Novena Época, Primera Sala, Semanario Judicial de la Federación y su Gaceta, t. XXIII, mayo de 2006, p. 133. 
concatenado permite que subsistan ambos tipos de criterios sin que se produzca una contradicción.

El criterio más prometedor en la materia es el del Segundo Tribunal Colegido del Décimo Primer Circuito. En esta tesis jurisprudencial se establece que una "defensa adecuada" debe "traducirse en actos procesales que revelen una asistencia técnica profesional". ${ }^{40}$ Esta tesis establece un estándar que podría ser el inicio de un proceso casuístico que permitiera, a los jueces constitucionales, definir las características sustantivas de una defensa real y efectiva. Sin embargo, como en México la jurisprudencia se independiza de las decisiones que le dieron origen, lo más probable es que esta tesis jurisprudencial quede aislada y sin mucho impacto en la práctica judicial.

A manera de hipótesis, que habría que verificar empíricamente, nosotras estimamos que tiene mucha más probabilidad de ser aplicada en futuros litigios una tesis formalista que una sustancialista, pues las primeras dan instrucciones claras a los jueces inferiores, mientras que las segundas requieren de un mayor proceso de análisis y capacidad argumentativa por parte del juez vinculado a ellas.

En este sentido, es posible suponer que la ausencia de criterios jurisprudenciales sustantivos y la inexistencia de un proceso concatenado entre los razonamientos de las decisiones constitucionales sean fenómenos que están estrechamente relacionados: la falta de lo primero explica la ausencia de lo segundo y viceversa.

3. La ausencia de costos o consecuencias legales en el proceso producto de la mala calidad de la defensa.

Cuando los jueces tienen facultades para establecer jurisprudencia deben tomar en cuenta que sus decisiones no sólo tienen que ver con el pasado y las partes que acudieron a juicio, sino también con el futuro y la sociedad. Ello es particularmente cierto en el caso de las decisiones constitucionales de la Suprema Corte y los tribunales colegiados. Una forma de evaluar la dimensión prospectiva de sus sentencias es analizarlas en términos de incentivos: ¿cómo la sentencia coloca incentivos para que los operadores jurídicos no repitan en el futuro las mismas violaciones a la Constitución?

40 Tesis XI.2o. J/11 del Segundo Tribunal Colegiado del Décimo Primer Circuito, Semanario Judicial de la Federación y su Gaceta, t. VII, febrero de 1998, p. 46. 
La jurisprudencia constitucional del derecho a una defensa adecuada no ha colocado los incentivos correctos para que los ministerios públicos y los jueces penales modifiquen los patrones de conducta propios de un sistema político autoritario. Por ello, el Ministerio Público y el juez penal han podido seguir operando con "defensores" inexistentes en términos reales sin violentar ninguna de las tesis jurisprudenciales en la materia. También por ello, la defensoría pública en el ámbito local es una de las instituciones más abandonadas del país.

En las agencias del Ministerio Público, como señalamos, la práctica común es "simular" la existencia de una defensa a partir de la persona de confianza. Gracias a esta simulación, todos los derechos constitucionales del detenido son violados en forma sistemática. La Corte y los tribunales colegiados podrían terminar con dicha simulación impidiendo que la persona de confianza sea el único defensor y, a la vez, garantizando que la defensa cumpla con un conjunto de características sustantivas básicas. Ello lo lograrían de dos maneras. En primer término interpretando sustantivamente la cláusula constitucional de "defensa adecuada". Y, en segundo, estableciendo que si en la agencia del Ministerio Público se viola este derecho, la acusación no podrá prosperar en el juicio, es decir, el juez penal deberá estar obligado a dictar auto de libertad. Ambas cuestiones colocarían los incentivos para que el Ministerio Público deje de simular que el detenido contó con la una defensa a través de la persona de confianza y comience a garantizarle un abogado que lo defienda.

Por lo que toca a la fase de juicio, la defensa es inexistente pues los jueces constitucionales se han conformado con que el defensor, público o privado, esté presente en todos los actos procesales y dicha presencia se comprueba con la sola firma del defensor en las constancias de autos. Gracias a ello, en la práctica, la mayoría de los acusados, sobre todo los que atiende el defensor público, no tienen una defensa legal adecuada. El juez penal sólo debe verificar que estén todas las firmas del defensor en el sitio que les corresponde, haya o no estado presente en las diligencias procesales, para demostrar al juez de amparo que el proceso cumplió con los requisitos constitucionales de una defensa legal adecuada para el acusado.

Para modificar estas prácticas autoritarias, los jueces constitucionales tendrían que definir las características básicas de una defensa adecuada y establecer que si no se cumplen esas características, el juez tendrá que reponer el procedimiento. Ello significaría colocar los incentivos en el lu- 
gar correcto, pues los jueces penales buscarán evitar tener que volver a instruir el proceso de principio a fin.

En suma, los altos niveles de arbitrariedad que padece un inculpado desde el momento de la detención hasta la sentencia, están directamente relacionados con la inadecuada configuración jurisprudencial de sus derechos constitucionales. En concreto, con la ausencia de criterios jurisprudenciales que tengan como propósito modificar las prácticas autoritarias del sistema penal mexicano. La Suprema Corte y los tribunales colegiados deben hacerse cargo de la dimensión axiológica o material de los derechos fundamentales y ello, necesariamente, significa modificar la forma en que se genera, utiliza y publica la jurisprudencia en México.

Finalmente, lo que está en juego para poder resolver los problemas centrales que tiene la jurisprudencia constitucional es la posibilidad de que Poder Judicial federal abandone las viejas prácticas judiciales propias de un sistema político autoritario y las sustituya por las prácticas que caracterizan a los jueces constitucionales en una democracia. Esta transformación es una verdadera "revolución judicial". No hay nada más difícil, en términos de una reforma judicial, que modificar la mentalidad de los jueces y el método con el que argumentan sus decisiones. ¿Cómo lograrlo? Ello es el mayor desafío que tiene enfrente el Poder Judicial de la Federación.

Anexo 1. Tesis y jurisprudencias que no tienen relación con el papel del defensor. Se presentan por número de registro, ya que de esta manera es más fácil localizarlas en el sistema IUS de la Corte.

\begin{tabular}{|l|l|c|c|}
\hline \multicolumn{1}{|c|}{ Tema } & \multicolumn{1}{|c|}{ Contenido } & Tesis & Jurisprudencias \\
\hline $\begin{array}{l}\text { Otras mate- } \\
\text { rias }\end{array}$ & $\begin{array}{l}\text { En esta sección se recopila- } \\
\text { ron aquellos criterios que se }\end{array}$ & $173919,174118,174746$, & 175265,176260, \\
& filtraron pertenecientes a & $174714,176067,177443$, & 190889,192494, \\
& materias diversas a la penal & $178147,179939,179760$, & $193702,194291$. \\
& (administrativa, agraria,, & $185771,186186,186750$, & \\
& etc.) & $190619,190651,193967$, & \\
& & $195249,197343,173919$, & \\
& & $198288,198964,201330$, & \\
& & $202532,202594,202605$, & \\
& & $200660,204168,204636$, & \\
& & $204700,204839,200247$, & \\
& & $198705,197490,177465$, & \\
\hline
\end{tabular}




\begin{tabular}{|c|c|c|c|}
\hline $\begin{array}{l}\text { En nombre en } \\
\text { el proceso pe- } \\
\text { nal }\end{array}$ & $\begin{array}{l}\text { Este es el mayor conjunto } \\
\text { en donde se concentran in- } \\
\text { finidad de asuntos y en el } \\
\text { que aparece el término de } \\
\text { defensor para referirse a } \\
\text { aquellos actos en los que el } \\
\text { mismo actúa en nombre del } \\
\text { inculpado. Por ejemplo, } \\
\text { cuando el inculpado o su } \\
\text { defensor interpongan el re- } \\
\text { curso de apelación, etc. }\end{array}$ & $\begin{array}{l}83 \\
174656,175136,175135, \\
175175,176495,177693, \\
179389,179432,179885, \\
181746,182180,183224, \\
188321,187610,190193, \\
192397,195040,195882, \\
201738,202703,203499, \\
204929,173110,172763, \\
173109,173378,173502, \\
176388,176601,176598, \\
176826,177196,177708, \\
180076,180908,181042, \\
181300,181723,182072, \\
183164,183152,183116, \\
183187,183174,183934, \\
184218,184073,184316, \\
184350,184697,185078, \\
185826,185859,186357, \\
188576,189210,189516, \\
189817,189931,189895, \\
190215,190487,191244, \\
192669,194008,193973, \\
194209,195766,196005, \\
196674,201084,201790, \\
202014,202167,202538, \\
202821,203548,203859, \\
203978,204810,173278, \\
202158,180404,198038, \\
190950,196541 .\end{array}$ & \begin{tabular}{l}
\multicolumn{1}{|c}{21} \\
197380,204739, \\
204879,173113, \\
175021,177373, \\
178055,180274, \\
180718,180756, \\
181038,182128, \\
182690,182888, \\
184461,187120, \\
188198,188661, \\
190299,190790, \\
175937.
\end{tabular} \\
\hline $\begin{array}{l}\text { No en nom- } \\
\text { bre }\end{array}$ & $\begin{array}{l}\text { Cuando no puede el defen- } \\
\text { sor fungir en representa- } \\
\text { ción del inculpado. }\end{array}$ & \begin{tabular}{l}
\multicolumn{1}{c}{7} \\
180815, 182885, 186736, \\
188251, 189197, 194342, \\
199515. \\
\end{tabular} & 0 \\
\hline Otras & $\begin{array}{l}\text { Cuando se le debe suplir la } \\
\text { queja al MP. }\end{array}$ & $\begin{array}{c}3 \\
179488,179377,183640\end{array}$ & 0 \\
\hline Careos & $\begin{array}{l}\text { Hacen referencia a cómo } \\
\text { debe desahogarse dicha } \\
\text { audiencia. }\end{array}$ & $\begin{array}{l}11 \\
\text { 180187, 188284, 188283, } \\
\text { 190024, 199090, 201100, } \\
\text { 202611, 203559, 204932, } \\
179982,198983 .\end{array}$ & $\begin{array}{c}2 \\
185435,204362 .\end{array}$ \\
\hline
\end{tabular}




\begin{tabular}{|l|l|c|c|}
\hline $\begin{array}{l}\text { Copias en la } \\
\text { a.p. }\end{array}$ & $\begin{array}{l}\text { Hacen referencia a que el } \\
\text { inculpado puede pedir co- } \\
\text { pias del expediente aún en } \\
\text { esta etapa procesal. }\end{array}$ & $\begin{array}{l}10 \\
182429,183314,184212, \\
188028,190705,192882, \\
195347,198793,184696, \\
179989 .\end{array}$ & 0 \\
\hline $\begin{array}{l}\text { Menores in- } \\
\text { fractores }\end{array}$ & $\begin{array}{l}\text { Se refiere al proceso para } \\
\text { menores infractores. }\end{array}$ & 1 & 0 \\
\hline $\begin{array}{l}\text { Defensor no } \\
\text { es autoridad } \\
\text { responsable }\end{array}$ & $\begin{array}{l}\text { Para efectos del juicio de } \\
\text { amparo, el defensor no es } \\
\text { autoridad responsable. }\end{array}$ & 186788. & 0 \\
\hline $\begin{array}{l}\text { Suplencia de } \\
\text { la queja al } \\
\text { defensor }\end{array}$ & $\begin{array}{l}\text { Cuando procede suplirle } \\
\text { la queja al defensor. }\end{array}$ & $\begin{array}{l}\mid c \\
188462,195058,199581, \\
199979,200877 .\end{array}$ & $\begin{array}{l}204199,172883, \\
187216,197279, \\
197492,198493, \\
181429 .\end{array}$ \\
\hline Total & \multicolumn{1}{|c|}{152} & 29 \\
\hline
\end{tabular}

Criterios respecto al papel del defensor

\begin{tabular}{|c|c|c|c|}
\hline Tema & Justificación & Tesis & Jurisprudencias \\
\hline Presencia & $\begin{array}{l}\text { Tratan respecto que el de- } \\
\text { fensor debe estar presente en } \\
\text { las audiencias en las diferen- } \\
\text { tes etapas procesales. }\end{array}$ & $\begin{array}{c}35 \\
176335,201646,178654, \\
202388,202689,198947, \\
176710,177073,177032, \\
177702,178101,179684, \\
180021,185307,187583, \\
190502,194343,175137, \\
177642,178656,179608, \\
179607,181157,185785, \\
190025,197342,176336, \\
173837,174133,184532, \\
187005,187312,192953, \\
183173,188372 .\end{array}$ & $\begin{array}{l}22 \\
175110,186707, \\
175976,181578, \\
178762,179663, \\
179638,196751, \\
174938,176746, \\
177074,178529, \\
180717,185261, \\
185252,187313, \\
188682,195728, \\
198232,201837, \\
203511,200438 .\end{array}$ \\
\hline $\begin{array}{l}\text { C u a n d o } \\
\text { procede la } \\
\text { designa- } \\
\text { ción }\end{array}$ & $\begin{array}{l}\text { Cuando puede o debe ser de- } \\
\text { signado el defensor de ofi- } \\
\text { cio. }\end{array}$ & $\begin{array}{c}15 \\
193524,177324,193214, \\
198022,186036,194560, \\
195315,197968,201998, \\
190453,203350,181158, \\
184818,189126,190617 .\end{array}$ & $\begin{array}{c}4 \\
193216,203148, \\
193217,193202 .\end{array}$ \\
\hline
\end{tabular}




\begin{tabular}{|c|c|c|c|}
\hline $\begin{array}{l}\text { Quién pue- } \\
\text { de ser de- } \\
\text { fensor }\end{array}$ & $\begin{array}{l}\text { Se refiere a las característi- } \\
\text { cas que debe reunir el defen- } \\
\text { sor para poder fungir como } \\
\text { tal. }\end{array}$ & $\begin{array}{c}3 \\
172863,195549,186300 .\end{array}$ & $\begin{array}{c}6 \\
175109,203691 \\
188418,191976 \\
191975,195047 .\end{array}$ \\
\hline $\begin{array}{l}\text { Negligen- } \\
\text { cia del de- } \\
\text { fensor }\end{array}$ & $\begin{array}{l}\text { Cuando se configura la ne- } \\
\text { gligencia del defensor. }\end{array}$ & $\begin{array}{c}2 \\
192223,204829 .\end{array}$ & 0 \\
\hline $\begin{array}{l}\text { Delito de } \\
\text { abogados }\end{array}$ & $\begin{array}{l}\text { Cuando se configura el deli- } \\
\text { to de abogados. }\end{array}$ & $\begin{array}{c}2 \\
182209,176727 .\end{array}$ & 0 \\
\hline $\begin{array}{l}\text { Cambio de } \\
\text { defensores }\end{array}$ & $\begin{array}{l}\text { No se viola la garantía a la } \\
\text { adecuada defensa si se cam- } \\
\text { bia de defensor o si se tienen } \\
\text { dos defensores }\end{array}$ & $\begin{array}{c}2 \\
173578,191510 .\end{array}$ & 0 \\
\hline $\begin{array}{l}\text { Conflicto } \\
\text { de intere- } \\
\text { ses }\end{array}$ & $\begin{array}{l}\text { Cuando existe un conflicto } \\
\text { de interés para el abogado. }\end{array}$ & 180666. & 0 \\
\hline $\begin{array}{l}\text { La adecua- } \\
\text { da defensa } \\
\text { no sólo es } \\
\text { tener de- } \\
\text { fensor }\end{array}$ & $\begin{array}{l}\text { Explica la adecuada defensa } \\
\text { más allá del derecho a tener } \\
\text { un defensor. }\end{array}$ & 0 & 200394 \\
\hline Total & & 58 & 33 \\
\hline
\end{tabular}

